ISSN 2079-9292

www.mdpi.com/journal/electronics

Review

\title{
Organic Photodetectors in Analytical Applications
}

\section{Eeshita Manna ${ }^{1,2}$, Teng Xiao ${ }^{2,3}$, Joseph Shinar ${ }^{2,3, *}$ and Ruth Shinar ${ }^{1,4, *}$}

1 Electrical \& Computer Engineering Department, Iowa State University, Ames, IA 50011, USA; E-Mail: eeshita@iastate.edu

2 Ames Laboratory-USDOE, Iowa State University, Ames, IA 50011, USA;

E-Mail: tengxiaocm@gmail.com

3 Physics \& Astronomy Department, Iowa State University, Ames, IA 50011, USA

4 Microelectronics Research Center, Iowa State University, Ames, IA 50011, USA

* Authors to whom correspondence should be addressed;

E-Mails: jshinar@iastate.edu (J.S.); rshinar@iastate.edu (R.S.);

Tel.: +1-515-294-8706 (J.S.); +1-515-294-5898 (R.S.).

Academic Editor: Mostafa Bassiouni

Received: 23 July 2015 / Accepted: 16 September 2015 / Published: 23 September 2015

\begin{abstract}
This review focuses on the utilization of organic photodetectors (OPDs) in optical analytical applications, highlighting examples of chemical and biological sensors and lab-on-a-chip spectrometers. The integration of OPDs with other organic optical sensor components, such as organic light emitting diode (OLED) excitation sources and thin organic sensing films, presents a step toward achieving compact, eventually disposable all-organic analytical devices. We discuss recent advances in developing and integrating OPDs for various applications as well as challenges faced in this area.
\end{abstract}

Keywords: organic photodetectors; organic electronics in analytical applications; integrated sensors; lab-on-a-chip; spectrometer-on-a-chip

\section{Introduction}

There is a growing need for compact, user friendly, inexpensive, field-deployable integrated chemical and biological sensors, including multi-sensor arrays, with a demand for continued miniaturization [1] so that they can be integrated into many systems such as wearable electronics. Such sensors will 
replace current sensors that are often bulky or costly and require trained personnel for their operation. The sensors are needed for various applications, including water and food quality monitoring, health monitoring, medical testing, and security inspection [1]. They should be reliable, as well as sensitive and selective. Optical sensors are typically very sensitive [1]. Such sensors include an excitation source, a sensing element, a photodetector (PD), and the electronic circuitry. The sensing element is often an organic thin film with an embedded dye, whose photoluminescence (PL) intensity and decay time are affected by the presence and concentration of an analyte. Thin film technology, in particular organic electronics, is promising to fulfill this need of small size, reliable sensors. However, development and improvement of the various sensor components are still required. Similar to bio/chemical sensors, other on-chip optical devices such as spectrometers are of interest and thin film PDs, organic or hybrid, are promising for advancing such tools.

Organic electronics has already established its significant role in cutting edge technology due to the rapid development of organic light emitting diodes (OLEDs), organic transistors, and more recently organic photodetectors (OPDs). The use of organic thin-film devices is not limited to flat-panel displays and solid-state lighting. Organic electronics plays an important role in analytical and bioelectronics applications. As an example, OLED-based luminescent sensors are sensitive with the ability to be integrated with sensing films, thin film PDs, and microfluidic structures [2-4]. Indeed, OLEDs have been extensively researched as excitation sources for photoluminescence (PL)-based integrated oxygen and $\mathrm{pH}$ sensors, integrated oxygen and humidity sensors, glucose and other bioanalyte sensors, various immunoassays, and for on-chip spectrometers [5,6]. Since optical sensors rely on the interaction between the sensing material and light from the excitation source, precise and sensitive detection of a signal originating from the sensing film is key in determining the device performance. Initially, OLEDs were integrated with a sensing film fabricated on the opposite side of a common substrate, but to achieve a sensitive and specific detection a photomultiplier tube (PMT) was commonly used $[7,8]$. Though optical sensors with a PMT have a very high signal to noise ratio (SNR) and fast response time $[9,10]$, the PMT is highly magnetic-field sensitive and bulky, which prevents scaling down sensors with it and the sensor's use is limited to a magnetic-free environment.

The demand for small scale analytical instrumentation in research as well as in industry has led to the development of lab-on-a-chip (LoC) technology. The LoC technology attempts to create small scale analytical devices, which can be achieved via component integration. In optical sensors this entails integration of the excitation source, the sensing element, and the PD on a single, including microfluidic, chip [4]. The rapid growth of LoC usage in laboratory environment requires smaller PDs instead of a PMT to enable on-chip integration. Inorganic PDs have served this purpose well with an additional built-in preamplifier on the chip to enhance the detected signal $[11,12]$. However, CMOS and other inorganic thin film deposition procedures often require high processing temperatures and as a result are not cost effective for use in disposable devices. OPDs can be a good alternative to their inorganic variant due to their low temperature processing suitability and fabrication on simple substrates such as glass or plastic, which makes them flexible in size and design and hence compatible with microfluidic architectures. Though OPDs are not yet commercially available and are mostly being used in research and development areas, they present a potential for integration with LoC sensing devices because of their adaptable design, ease of fabrication, and unique simplicity of structural integration [13-15]. 
This review first discusses common OPD structures and their principle of operation. Next it describes the progress in OPD use in analytical applications via specific examples and presents issues that need to be mitigated to lead to compact and eventually disposable optical analytical devices. The review concludes with the recent development of hybrid PDs and an outlook.

\section{Organic Photodetectors: Working Principle}

PDs convert incident light to an electrical signal. There are various types of PDs, including PMTs, junction photodiodes, photoconductors/photoresistors, phototransistors, avalanche photodiodes, and charge-coupled devices (CCDs). OPDs are a more recent area of study. Their structure is basically that of an organic solar cell (OSC) though in contrast to OSCs they are often operated at a negative, typically small, bias. This negative bias leads to an internal field greater than the built-in field, which improves the photosensitivity and response speed. The signal increases with increased negative bias, however, the dark current (leakage current) increases as well. Low dark current is necessary for optimal PD performance and lower noise. The dark current can be reduced also by optimizing the morphology of the active layer and using a proper electron- or hole-blocking layer. OPDs are comprised of metal electrodes and $\pi$-conjugated polymers or organic small-molecules as donors with typically fullerene derivatives as acceptors. The standard structure of an OPD is indium tin oxide (ITO) (anode)/hole transport (extraction) layer (HTL)/ $\pi$-conjugated polymer-based bulk heterojunction or small molecule-based multiple donor-acceptor layers/electron transport (extraction) layer (ETL)/Ca/Al (cathode). The typical energy gap (1.5-3 eV) between the highest occupied molecular orbital (HOMO) and lowest unoccupied molecular orbital (LUMO) of such $\pi$-conjugated organic materials can be a good match for absorbing visible to near IR light. Figure 1 shows a typical schematic of a bulk heterojunction (BHJ) OPD and the energy diagram of a poly(3-hexylthiophene-2,5-diyl):(6,6)-phenyl $\mathrm{C}_{61}$ butyric acid methyl ester (P3HT:PCBM)-based device.



Figure 1. Schematic of a bulk heterojunction (BHJ) organic photodetector (OPD) structure and the energy diagram for a P3HT:PCBM-based OPD.

As mentioned, unlike inorganic semiconductors, organic thin films are processed at low temperatures and are therefore compatible with simple flexible substrates irrespective of the substrates' shape; these include wearable and plastic substrates [15]. Deposition techniques of the various thin 
layers include thermal evaporation (for $\pi$-conjugated organic small molecules), spin-coating (typically for polymers), spray-coating, screen printing, micro-printing, and roll-to-roll processing [16-19]. Importantly, the optical and electronic properties of an organic material can be tuned to make it compatible with a specific application [20].

There are generally four stages of converting light into electric current in photovoltaic devices. An excited electron-hole pair (exciton) state is formed by photons absorbed by the active layer. The generated excitons diffuse to an interface where charge separation occurs. The separated charges travel to the corresponding electrodes, where they are collected. The efficiency of an OPD corresponds directly to the number of created charges that are collected at the electrodes and this number depends on the fraction of photons that are absorbed, the fraction of excitons that dissociate to electrons and holes, and the charge collection efficiency at the electrodes. The OPD performance is enhanced by optimizing any of these factors. The spectral response of detectors can be tuned mostly by material choice and by adjusting the thickness of the resonant cavity sandwiched between two metal electrodes, using an optical spacer at the anode [21]. For instance, PTB7 (polythieno [3,4-b]-thiophene-cobenzodithiophene)-based OPDs absorb more in a longer wavelength range (550-750 nm) than the well-known P3HT-based OPDs. In addition to the material choice, there are also several novel methods utilizing light trapping or plasmonic effects to maximize absorption in the active layer to enhance exciton formation [22-25]. The exciton diffusion efficiency depends on where the excitons are formed and whether they can diffuse to the donor/acceptor (D/A) interface, where charge dissociation occurs. Since the exciton diffusion length is much smaller in organic materials than in their inorganic counterparts, bulk heterojunction (BHJ) structures are mostly used to ensure exciton formation very close to the D/A interface [26].

The charge collection highly depends on the carriers' mobility within the transporting layers. Reducing the density of deep traps, which act as recombination centers, whether originating from impurities or structural disorder, can improve carrier mobility. Indeed, carrier mobility was shown to increase with crystalline structure of the organic semiconductor formed during annealing [27].

Specifically, attributes that are important in characterizing OPDs include responsivity, external quantum efficiency (EQE)/gain, spectral response, dynamic range, response speed, response linearity, the noise equivalent power (NEP), detectivity, and stability. The ratio of the current or voltage output signal to the input power is defined as the responsivity, which improves with increasing EQE. A constant responsivity within a certain wavelength range or a linear responsivity is highly desired, so that the output signal can be predicted based on a given power input. In OPDs the EQE is typically less than $100 \%$, hence they typically have no internal gain.

High gain in OPDs was recently reported. In an OPD of the structure a ITO/poly(3,4-ethylenedioxythiophene):polystyrene sulfonate (PEDOT:PSS)/fullerene (C60)/2,9-dimethyl4,7-diphenyl-1,10-phenanthroline (BCP)/Al OPD [28]. The high gain was explained by a trapped hole-enhanced electron-injection process, where the photo-generated holes get trapped at the interface of the hole transport layer (PEDOT:PSS) and the active layer component ( $\left.\mathrm{C}_{60}\right)$. The high density of trapped holes reduces the electron injection barrier via band bending at the interface, which leads to secondary electron injection from the hole transport material to the active layer. A buffer layer to strongly reduce the dark current and increase the detectivity was inserted between the PEDOT:PSS and the $\mathrm{C}_{60}$ layers, but it eliminated the gain. 
As mentioned, the spectral response is the wavelength range in which OPDs can function properly. A given OPD can typically respond only to a specific wavelength range, and proper materials need to be selected to match the input optical signal. The dynamic range is defined as the ratio of the maximum and minimum detectable power in $\mathrm{dB}$. Another key attribute is the OPD's response time, which is characterized by the rise and fall times in response to an input signal. Also, a linear output over a broad range of light intensities is beneficial, and to get an accurate response the noise should be low. Obviously, the input power should be no less than the NEP, which is defined as the input power at which the SNR is unity.

Clearly, a high specific detectivity $\mathrm{D}^{*}$, which defines the ability of a PD to detect a small optical signal, is wanted; $\mathrm{D}^{*}$ equals the reciprocal of the NEP normalized to the square root of the sensor's area and frequency bandwidth in Jones units $\left(\mathrm{cm} \cdot \mathrm{Hz}^{1 / 2} \mathrm{~W}^{-1}\right)$, i.e.:

$$
\mathrm{D}^{*}=\frac{\sqrt{\mathrm{A} \times \Delta \mathrm{f}}}{\mathrm{NEP}}
$$

where $\mathrm{A}$ is the photosensitive area of the $\mathrm{PD}$ and $\Delta \mathrm{f}$ is the frequency bandwidth. Beyond all these factors, obtaining high stability insures reproducibility over time, which is a major challenge in OPDs.

\section{OPDs in Analytical Sensing}

The use of OPDs in analytical sensing is a multidisciplinary endeavor that involves optics, organic electronics, microfluidics (mechanical engineering), and chemical and biological sciences. OPDs can be employed in optical sensing in several ways, with the majority of the sensors utilizing two different luminescent processes, bio/chemiluminescence (CL) and/or photoluminescence (PL) [2-4]. In this review we highlight examples of OPDs' use in CL/PL sensors as well as in absorption measurements.

\subsection{Chemiluminescent Assays}

CL occurs during the progression of some chemical reactions where an electronically excited state is generated. CL sensors are utilized in immunoassays and for nucleic acid detection, where an emitting compound is used as a label [29]. Such sensors often utilize oxidation of a material in an excited state [30]. The emitted light intensity depends on the concentration of the reactive material or on the rate of the chemiluminescent reaction. Having no background emission from an external excitation source, the limit of detection (LOD) for these detection systems is very low.

Though the usage of CL in analytical applications is not new, compact, easy to use designs for, e.g., healthcare systems are yet to be developed [31-35]. An example of a point-of-care CL sensor set up includes a (poly)dimethylsiloxane (PDMS) microfluidic chip (made by soft lithography) with two inlets, one outlet and a reaction/detection chamber. The two inlets are connected to syringe pumps where the flowing rate of reagents can be controlled. Sometimes a third syringe pump is used to inject catalysts. The PD is located underneath or above the detection chamber.

Numerous studies have been reported on peroxyoxalate CL (POCL) sensors for monitoring $\mathrm{H}_{2} \mathrm{O}_{2}$ with a PMT [36-38] or a silicon photodiode [39-41]. Hoffman et al. showed [42] that these POCL sensors can be further miniaturized by successfully integrating an organic copper phthalocyanine/fullerene $\left(\mathrm{CuPc}_{\mathrm{C}} / \mathrm{C}_{6}\right)$ based OPD with PDMS microchannels. The EQE of this OPD was 
$30 \%$ at $600-700 \mathrm{~nm}$. With an optimized flow rate $(\sim 25 \mu \mathrm{L} / \mathrm{min})$ of POCL reagents, a steady state CL-induced photocurrent of $8.8 \mathrm{nA}$ was achieved within $11 \mathrm{~min}$ with excellent reproducibility. But although the photocurrent vs. $\mathrm{H}_{2} \mathrm{O}_{2}$ concentration was linear up to $1 \mathrm{M}$, the $\mathrm{H}_{2} \mathrm{O}_{2}$ LOD was only $1 \mathrm{mM}$, whereas with a PMT and Si photodiodes it was as low as $5 \mu \mathrm{M}$ [43]. An inadequate alignment of the detection chamber and the OPD, as the size of the $\mathrm{CuPc} / \mathrm{C}_{60}$ OPD $\left(16 \mathrm{~mm}^{2}\right)$ was larger than that of the microfluidic detection chamber $\left(2 \mathrm{~mm}^{2}\right)$, led to higher dark/background current $\sim 6 \mathrm{nA} / \mathrm{cm}^{2}$, which restricted the LOD significantly. Consequently Wang et al. [44] reported POCL detection with a solution processed P3HT:(6,6)-phenyl $\mathrm{C}_{61}$ butyric acid methyl ester (PCBM) OPD, where the OPD was comparable in size $\left(1 \mathrm{~mm}^{2}\right)$ and aligned properly with the detection chamber. With this geometry and OPD, a LOD of $10 \mu \mathrm{M} \mathrm{H} \mathrm{H}_{2}$ was achieved at an optimum flow rate of $75 \mu \mathrm{L} / \mathrm{min}$, which is comparable to the LOD obtained with a Si photodiode [43]. Later the same group successfully utilized this integrated system for antioxidant detection screening [45]. They injected various plant-based antioxidants, e.g., $\alpha$-tocopherol (vitamin E), $\beta$-carotene (vitamin A), and quercetin to the stream of POCL reagents in PDMS microfluidic channels to detect the antioxidant concentration in the aforementioned biological extracts. The CL signal was detected by the P3HT:PCBM OPD, which had a broadband photoresponse ranging from 350 to $650 \mathrm{~nm}$ with a peak responsivity of $0.25 \mathrm{~A} / \mathrm{W}$ at $550 \mathrm{~nm}$ and a dark current density of $0.59 \mu \mathrm{A} / \mathrm{cm}^{2}$. The results showed a linear trend of the CL intensity with the antioxidant concentration in the range of $\sim 2 \mu \mathrm{M}$ to $200 \mu \mathrm{M}$ and the LOD was comparable to that achieved with a PMT.

Wojciechowski et al. [46] presented the integration of a solution processed P3HT:PCBM OPD with a disposable biosensor chip that included a microfluidic channel with an immobilized capture antibody for Staphylococcal Enterotoxin B (SEB). The OPD monitored the CL from the biotinylated $\alpha$-SEB capture antibody/SEB/horseradish peroxidase (HRP)-conjugated $\alpha$-SEB antibody ( $\alpha$-SEB-HRP) assay. A LOD of $0.5 \mathrm{ng} / \mathrm{mL}$ was obtained due to a low dark current (noise) $\left(<10 \mathrm{nA} / \mathrm{cm}^{2}\right)$ obtained under a small reverse bias (up to $-100 \mathrm{mV}$ ). The reported LOD was comparable to that obtained with PMT and CCD-based detection.

Pires et al. reported a CL sensor [47] that consists of an immunoassay chip with biomolecules immobilized on an $\mathrm{Au}$ coated glass substrate and an optimized BHJ OPD with the structure ITO/PEDOT:PSS/poly[N-9'-heptadecanyl-2,7-carbazole-alt-5,5-(4',7'-di-2-thienyl-2',1',3'-benzothiadiazole)] (PCDTBT):PC70BM/LiF/Al. The immunoassay was employed to detect recombinant human thyroid stimulating hormone (rhTSH), a marker for diagnosis of thyroid cancer. In addition to using PCDTBT (instead of P3HT), which is known to lead to a higher short circuit current [48], the OPD was further optimized by changing the thickness of PEDOT:PSS and the active layer. Hence, a low LOD was obtained with the OPD monitoring the $\sim 425 \mathrm{~nm}$ CL signal due to the interaction between anti-rhTSH monoclonal antibody, rhTSH antigen, and a biotinylated secondary antibody complex together with HRP. Later Pires et al. integrated the PCDTBT:PC70BM-based OPD with a microfluidic biosensor for protein analysis [49]. For the detection of rhTSH, an excellent linearity in the range of 0.03 to $10 \mathrm{ng} / \mathrm{mL}$ was achieved with high sensitivity and reproducibility.

TSH detection in clinical samples was further demonstrated to verify the potential application of the biosensor in clinical testing. Following the successful detection of rhTSH; the same technique was employed for detecting the stress hormone cortisol using an appropriate antibody and fluorophor [50]. The same OPD was used due to its very low dark current $\left(\sim 17 \mathrm{pA} / \mathrm{cm}^{2}\right)$ and high EQE $(>60 \%)$; 
achieving a detection sensitivity of $1.775 \mathrm{pA} / \mathrm{nM}$ and a LOD $<0.28 \mathrm{nM}$ with the integrated system. Pires et al. have also reported a poly(methylmethacrylate) (PMMA) multiplexed microfluidic biosensor integrated into an array of OPDs (Figure 2) for CL detection of pathogens, e.g., waterborne Escherichia coli O157:H7; Campylobacter jejuni; and adenovirus [51]. The optimized PCDTBT:PC70BM-based OPD exhibited a responsivity $>0.20 \mathrm{~A} / \mathrm{W}$ at $425 \mathrm{~nm}$ for the multiplexed detection tests. Parallel analysis of the three inactivated bacteria mentioned earlier; in the spiked drinking and surface water samples; was achieved within $35 \mathrm{~min}$ and the LODs were $5 \times 10^{5}$ cells $/ \mathrm{mL}$ for E. coli; $1 \times 10^{5}$ cells $/ \mathrm{mL}$ for $C$. jejuni and $1 \times 10^{-8} \mathrm{mg} / \mathrm{mL}$ for adenovirus. The reported device can potentially be employed for simultaneous detection of up to sixteen analytes within a short period of time.

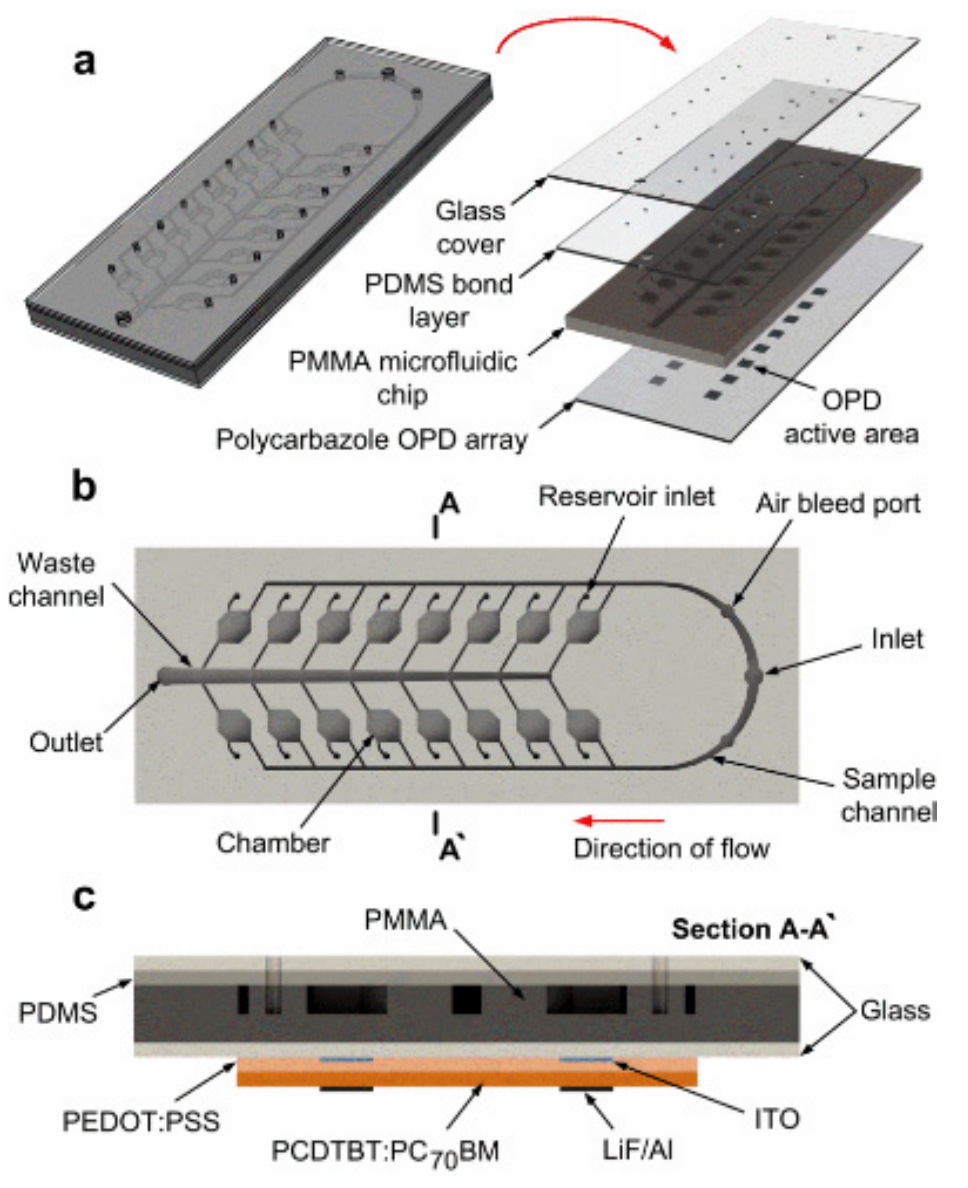

Figure 2. (a) Illustration of the multiplexed optical-biosensor platform integrating an array of polycarbazole OPDs to a hybrid microfluidic chip made of poly(methylmethacrylate) (PMMA) and (poly)dimethylsiloxane (PDMS); (b) Top view of the PMMA microfluidic substrate with $\sim 30 \mathrm{~mm}^{3}$ volume chambers; (c) Cross-section view of the integrated device illustrating all device components (not to scale) Reproduced with permission from Tao Dong from reference [51], Sensors, published by MDPI (2013).

Expanding this work, Dong and co-workers presented a concept of a capillary-driven sensing device integrated with an OPD [52]. The characterization of the proposed device model containing eight reaction chambers joined with microfluidic channels was done by finite element method simulations and the results were verified experimentally for a single chamber utilizing a CL reaction that occurred due to the HRP-luminol-peroxide interaction. However, differences in analytical sensitivity were 
noticed among the different chambers due to a non-uniform filling process. It was also demonstrated that the detection sensitivity of CL-based sensing can be improved by incorporating gold nanoparticles (AuNPs) with a PDMS-glass hybrid microfluidic chip [53]. Due to the enhancing effect of the AuNPs on HRP-luminol- $\mathrm{H}_{2} \mathrm{O}_{2} \mathrm{CL}$ and the very high detectivity of the PCDTBT:PC70BM BHJ OPD $\left(D^{*} \sim 9.2 \times 10^{11}\right.$ Jones under $0.22 \mathrm{~mW} / \mathrm{cm}^{2}$ irradiation at $428 \mathrm{~nm}$ ), the reported CL immunosensor was $\sim 200$ fold more sensitive than previously reported similar sensors achieving a very low LOD of $2.5 \mathrm{pg} / \mathrm{mL}$ for $17-\beta$ estradiol. This enhancement effect of AuNPs, when integrated with ring shaped OPDs and capillary-induced flow in microfluidic channels for field CL detection of a waterborne pathogen (Legionella pneumophila), resulted in a resolution of $4 \times 10^{4}$ cells $/ \mathrm{mL}$, with a 25 fold improvement over previously reported sensing without AuNPs [54].

\subsection{PL-Based Chemical/Biological Sensors}

PL-based sensors typically comprise an excitation source, a sensing element that is often a thin organic film or a solution with an analyte-sensitive dye, a PD, and the electronic circuitry. The excitation source is used for excitation of the sensing material whose PL depends on the dose of the analyte. Thin film PDs in PL-based bio/chem sensors have demonstrated high detection sensitivities with the advantages of simple fabrication and ease of integration in all-organic devices that are potentially low cost. That is, OPDs can be integrated with thin sensing films or microfluidic channels with the sensing element, and with OLED excitation sources to generate compact, yet sensitive monitors [55-59].

The structure of PL-based sensors is similar to that of CL sensors $[2,8,12]$, though the working principle is different. In PL-based sensors the analyte-dependent PL intensity I and/or decay time $\tau$ of the analyte-sensitive material are monitored. For example, optical monitoring of $\mathrm{O}_{2}$ is based on examining the quenching of $I$ and/or the decrease of $\tau$ of an excited oxygen-sensitive dye such as $\mathrm{Pt}$ octaethylporphyrin (PtOEP) or the Pd analog PdOEP. This quenching is due to collisions of the excited dye with $\mathrm{O}_{2}$ in a dynamic Dexter process [60]. Ideally this process is described by the Stern-Volmer (SV) Equation (2) [61].

$$
\frac{I_{0}}{I}=\frac{\tau_{0}}{\tau}=1+K_{\mathrm{SV}}\left[O_{2}\right]
$$

where $I_{0}$ and $\tau_{0}$ are the PL intensity and decay time, respectively, at $0 \%$ oxygen, and $I$ and $\tau$ are the values in the presence of oxygen. $K_{\mathrm{SV}}$ is the $\mathrm{SV}$ constant.

Structurally integrating a PL-based sensor would enable numerous point-of-care applications, however, for sensitive detection, a strong excitation source to excite the sensing material is needed. When using a lamp, an OLED, or an inorganic LED, an optical filter or other means are often essential for suppressing the excitation light from reaching the PD [62,63]. Banerjee et al. used a broadband halide lamp (narrowed by a band pass filter) for excitation of $1 \mu \mathrm{L}$ rhodamine $6 \mathrm{G}$ dissolved in ethanol and contained in a PDMS microfluidic channel. A $\mathrm{CuPc} / \mathrm{C}_{60}$-based OPD was used for generating a cost effective detection [64]. To address the issue of interfering light from the excitation source the authors devised a cross-polarized scheme, where the excitation light passed through a linear polarizer and the dye's fluorescence (and the excitation light) passed through a second linear polarizer placed orthogonally to the former. As a result, the photocurrents measured by the $\mathrm{CuPc} / \mathrm{C}_{60}$-based $\mathrm{OPD}$ due to 
the excitation source (without the sensing component) and the dye's PL reduced by $25 \mathrm{~dB}$ and $3 \mathrm{~dB}$, respectively improving the SNR. Hence, utilizing this approach, the signal from analytical assays monitored by an OPD can be significantly improved. With this system, a LOD of $10 \mathrm{nM}$ was obtained for several fluorescent dyes such as the common rhodamine $6 \mathrm{G}$ and fluorescein. Next, Banerjee et al. replaced the halide excitation lamp with a green tris(8-hydroxyquinolinato) aluminum (Alq3)-based OLED [65-67], however, a higher $100 \mathrm{nM}$ LOD was obtained with this on-chip design. The LOD was lowered to $10 \mathrm{nM}$ by using an alternating $\mathrm{CuPc} / \mathrm{C}_{60}$ bilayer $\mathrm{OPD}$, which has a responsivity 10 fold better than that of a single layered heterojunction OPD [66].

Kraker and co-workers addressed the SNR due to the interfering excitation light in a similar approach [68]. They used polarizer foils as substrates as well as filters, filtering out the excitation light of a green Alq3-based OLED (for oxygen sensing) and of a blue OLED (for $\mathrm{pH}$ monitoring). A CuPc/perylene-tetracarboxylic bisbenzimidazole (PTCBI)-based OPD was used for detection of luminescent Pt(II)meso-tetra(pentafluorophenyl)porphine (Pt-TFPP) embedded in a polystyrene matrix and fluorescein isothiocyanate (FITC) in a $\mathrm{pH}$ buffer solution for oxygen and $\mathrm{pH}$ monitoring, respectively.

Optical wave-guiding can also be employed to increase the SNR and eliminate the need for optical filters [69-73]. Mayr and co-workers [69,70] developed such a sensor array with integrated OPDs, where optical filters were not required due to the platform's geometry (Figure 3), which enabled separation of the excitation light from the PL signal. As shown in the figure, ring-shaped OPDs were fabricated on the back side of a glass slide or on a polymeric substrate and the sensing film was prepared either on the opposite side of the substrate (for PL-based sensing) or immobilized inside the waveguide layer (Figure 3b) (for absorption-based sensing). For the PL sensor, the sensing film was illuminated by a $450 \mathrm{~nm}$ LED through an aperture and the sensing signal was guided through a substrate with a higher refractive index toward the ring shaped OPD array. In this case, a stable fluorophore is excited by the LED and the emitted guided fluorescence is partially absorbed by an immobilized absorber and then deflected toward the OPD array by a scatterer. The OPDs were chosen to be a p-n heterojunction diode based on CuPc:PTCBI due to their compatible spectral response with the sensing elements and high on/off ratio $(64 \mathrm{~dB})$, i.e., high photocurrent/dark current ratio. The OPDs were stable under non-inert conditions and exhibited minimal degradation at $0 \mathrm{~V}$. The ring-shaped OPD geometry was successfully employed to monitor oxygen, carbon dioxide, relative humidity, and $\mathrm{pH}$ in aqueous and gaseous media.

In 2010, Nalwa et al. demonstrated a structurally integrated all organic sensing platform, which included an OLED excitation source, a dye for oxygen and glucose sensing, and a P3HT:PCBM OPD [74]. The spectral response of the P3HT:PCBM-based OPD was tuned to achieve a better photoresponse for the red emission of the PtOEP sensing dye. A thicker and slower-grown P3HT:PCBM BHJ layer was generated for this reason and it resulted in a $40 \%$ EQE at $\sim 640 \mathrm{~nm}$, the peak emission of the sensing dye. Oxygen and glucose concentrations were monitored using this optimized OPD via detection of the phosphorescence $I$ and $\tau$ of the dye (Equation (2); first temporal measurement for an all-organic device). In particular, the fast response of the OPDs enabled oxygen detection using the $\tau$ mode. Figure 4 shows the oxygen and glucose monitoring results. 

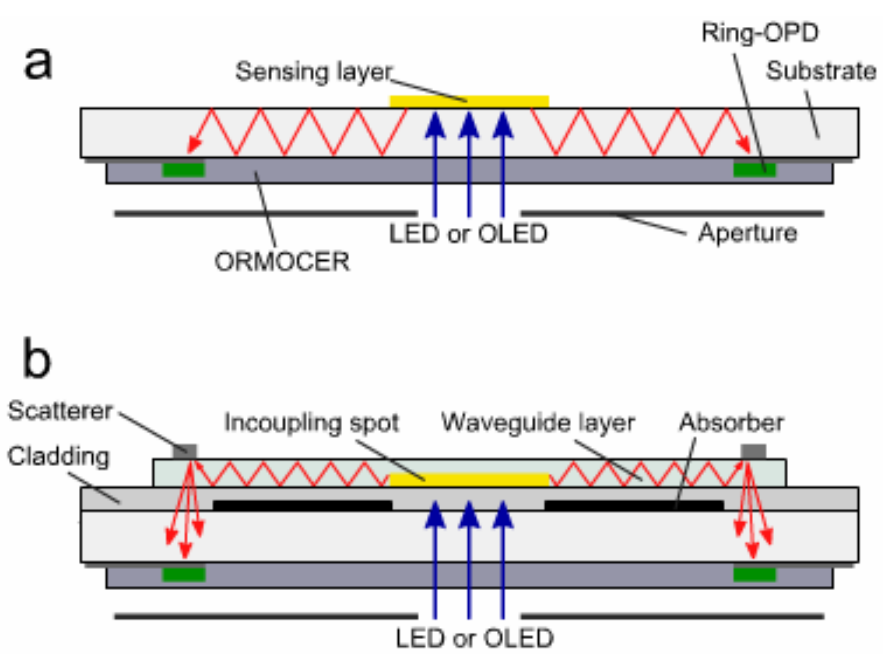

Figure 3. Schematic side view for the luminescence-based (a) and absorption-based (b) sensor chip (sizes are not to scale). The figure is reused from reference [70] (C) Springer-Verlag 2012 with kind permission from Springer Science and Business Media.
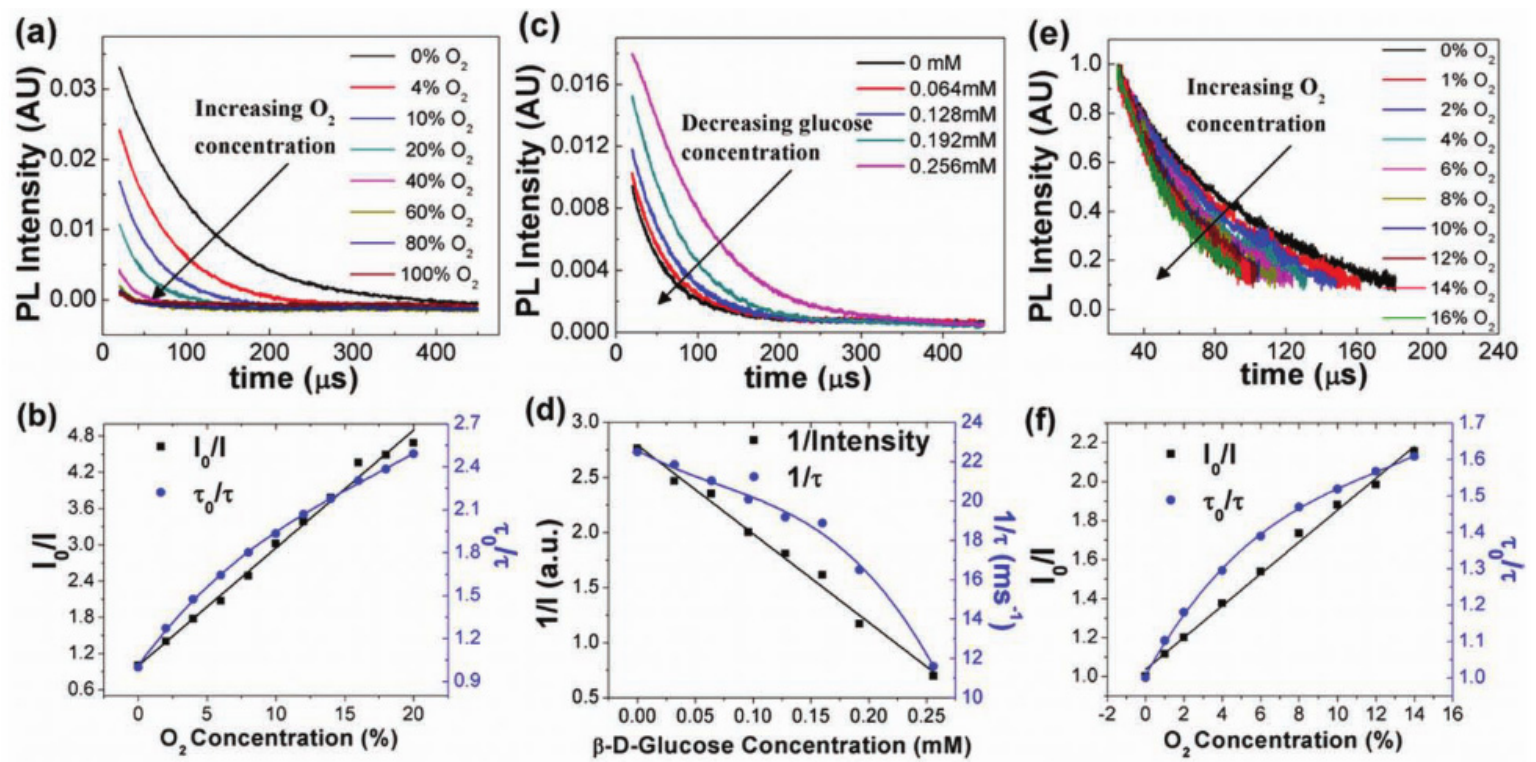

Figure 4. The effect of concentration of gas-phase $\mathrm{O}_{2}(\mathbf{a}, \mathbf{e})$, and of glucose (c) on the OPD's temporal photocurrent response. The excitation sources were LED (for (a-d)) and OLED (for (e-f)). Figure reused with permission from reference [74] Copyright (C) 2009 John Wiley \& Sons, Inc.

Later Liu et al. [75] addressed different challenges that limit the LOD in all organic integrated sensors. These challenges include the OLEDs' broad EL band, the OLEDs' low (forward) outcoupling factor, and the transient EL profile (i.e., the EL vs. time following an OLED pulse), including the long EL temporal tail in some OLEDs, in particular in guest-host OLEDs [76]. To achieve a high sensitivity from an all organic integrated detector, Liu et al. [75] used narrower band emission green and blue microcavity OLEDs ( $\mu \mathrm{cOLEDs}$ ). The narrower EL improved the SNR significantly. Furthermore adding polyethylene glycol (PEG) to the PtOEP:PS sensing matrix resulted in a porous microstructure that served a dual purpose: It led to an increase in the absorption by the dye due to scattering by voids 
that increased the optical path of the excitation source, and as a result increased the PL. Apparently it also increased the phosphorescence that was directed toward the OPDs, and a PEG:PS film (devoid of the dye) was used also to enhance the OLEDs' outcoupling factor. Though adding PEG to the sensing matrix reduced the detection sensitivity by a factor of 1.7 , it enhanced the PL signal by $\times 2.7$, which is crucial when using OPDs. In the all organic sensors, it was shown that the small molecule $\mathrm{CuPc} / \mathrm{C}_{70}$-based OPD is preferred for red PL over the P3HT:PCBM OPD that has a stronger responsivity for the green excitation light. Using both $\mathrm{CuPc} / \mathrm{C}_{70}$ and P3HT:PCBM OPDs (Figure 5a), a dual sensing platform for dissolved $\mathrm{O}_{2}$ (DO) and $\mathrm{pH}$ monitoring was demonstrated using green and blue $\mu$ cOLEDs, respectively.
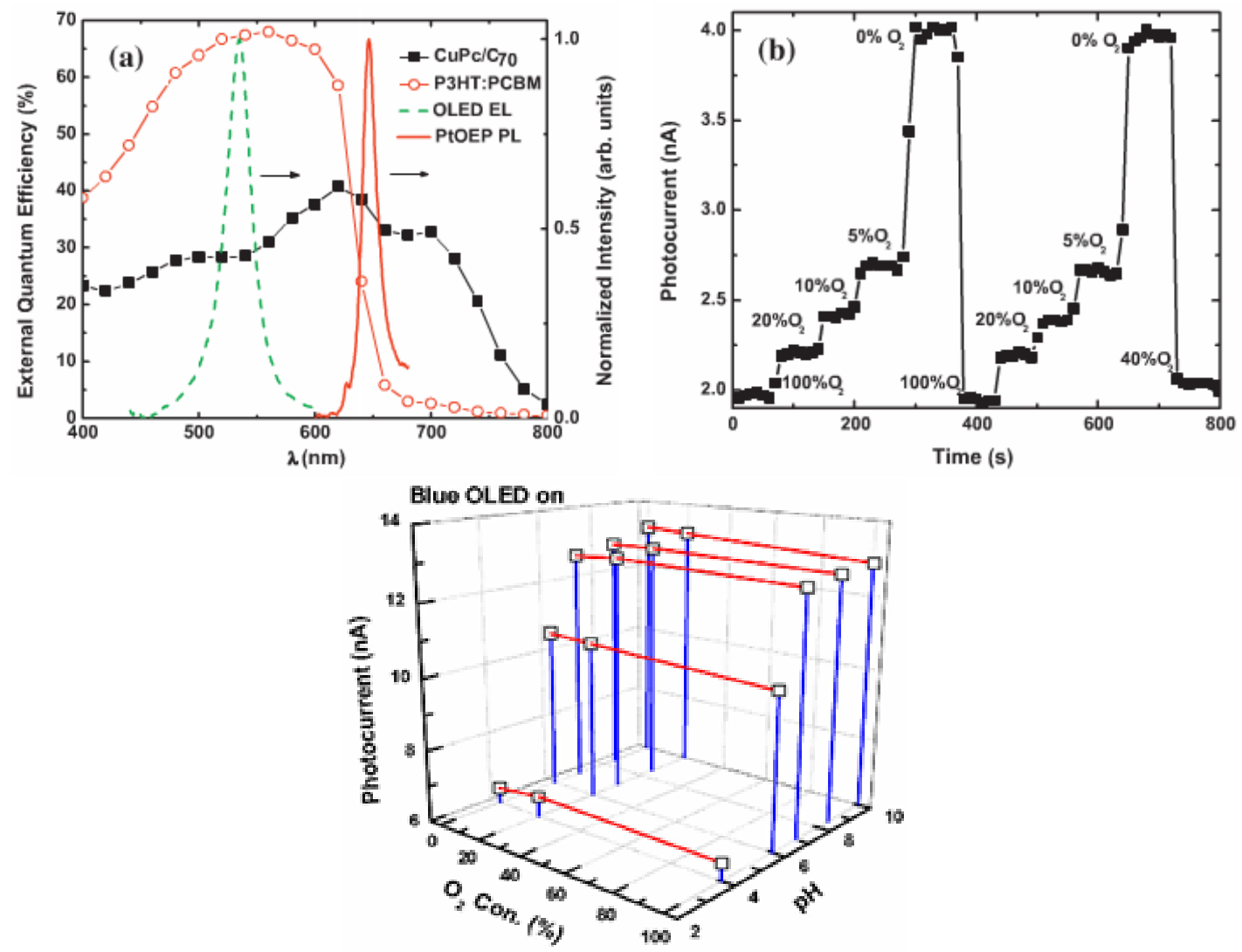

(c)

Figure 5. (a) External quantum efficiency (EQE) of CuPc/C70 (black) and P3HT:PCBM (red)-based OPDs, the electroluminescence (EL) of the microcavity $(\mu \mathrm{c})$ organic light emitting diode (OLED) (dashed green line), and PL of the sensing film (solid red line); (b) The sensing signal excited by the $\mu \mathrm{cOLED}$ detected by $\mathrm{CuPc} / \mathrm{C}_{70} \mathrm{OPD}$ at various $\mathrm{O}_{2}$ concentrations; (c) The signal intensity detected by the P3HT:PCBM OPD at different $\mathrm{O}_{2}$ and $\mathrm{pH}$ levels with the blue $\mu \mathrm{cOLED}$. Reprinted from reference [75] Copyright (2013), with permission from Elsevier B.V.

Extending the previous work, Manna et al. [77] replaced the green $\mu$ cOLED with a near UV $\mu \mathrm{cOLED}$ as the excitation source for an all-organic oxygen sensor. Since the oxygen sensitive dyes PtOEP and PdOEP have a stronger absorption in the near UV, the use of the near UV device significantly enhanced the SNR. Moreover, a more sensitive PTB7:PCBM-based OPD was used 
instead of P3HT:PCBM due its higher photoresponse at the longer wavelength range compared to the wavelength range of the excitation source. The PTB7:PCBM-based OPD, together with near UV $\mu \mathrm{cOLED}$, enabled monitoring the entire range $(0 \%-100 \%)$ of oxygen level in contrast to the green excitation source that exhibited a lower SNR.

Lefèvre and co-workers reported the first miniaturized all organic fluorescent sensor integrated into a microfluidic chip [78]. A blue 4,4'-bis-(2,2-diphenyl-ethen-1-yl) biphenyl (DPVBi) OLED was used as the excitation source and a PTB3:PC $61 \mathrm{BM}$ BHJ as the OPD. The OPD was highly sensitive at 600-700 nm with an EQE of 47\% at $685 \mathrm{~nm}$, and thus it was appropriate for detecting fluorescence of green algae (Figure 6b). The detection system was integrated with a PDMS microfluidic chip with two color filters to prevent undesired light from the excitation source from reaching the OPD; the filter blocking the longer wavelength part of the OLED's emission was between the microfluidic chip and the OLED, while the filter for blocking the excitation light was between the microfluidic chip and the OPD. The sensor was used for pollutant detection. A $10 \mu \mathrm{L}$ of $1 \times 10^{6}$ cells $/ \mathrm{mL}$ green algal culture (Chlamydomonas reinhardtii (CC-125)) mixed with herbicide Diuron was excited by the pulsed blue OLED and the fluorescence from the algal chlorophyll was measured by the OPD. The OPD was operated under zero bias, keeping the dark current at $<1 \mathrm{nA} / \mathrm{cm}^{2}$. The fluorescence of the green algae enabled the evaluation of the number of algal cells present in the medium and the toxic effects of the Diuron pollutant at a concentration as low as $11 \mathrm{nM}$. Figure 5 shows the spectra of the three sensor components (OLED's EL, absorption and fluorescence of green algae, and EQE of the OPD) in the integrated setup; the algae's fluorescence as measured by the OPD, and for comparison, by a commercial fluorometer.

Bradley and coworkers [79] demonstrated a compact, low cost, and practical fluorescence detection system (Figure 7a) for potential lab-on-a-chip/point of care testing applications using a commercially available InGaN LED (501 $\mathrm{nm})$ as the excitation source, polystyrene microfluidic chip for fluorescence immunoassays and a P3HT:PCBM OPD for detection of the two cardiac markers myoglobin and CK-MB. They used both absorptive dye coated color filters and linear and reflective polarizers to suppress the background due to LED's leakage EL and to enhance the SNR. The performance of the OPD was compared to that of a low cost commercial large area Si PD with a similar spectral response. Diluted fluorescent beads TransFluoSphere ${ }^{\circledR}$ were used to determine the optical LOD of this sensor setup. The EQE of the BHJ P3HT:PCBM OPD exceeded 40\% across the wavelength range of $400-600 \mathrm{~nm}$ due to its strong absorption in this range, with a peak EQE of $58 \%$ at $520 \mathrm{~nm}$, whereas the peak EQE of the Si PD was $\sim 19 \%$ at $560 \mathrm{~nm}$ as shown in Figure $7 \mathrm{~b}$ (we note that this commercial Si PD is likely not the state of the art). The (undesired) 4\% EQE in the longer wavelength range of the Si PD also reduced the SNR. The OPD was thus proven to be a good match for the TransFluoSphere ${ }^{\circledR}$ emission band (570-700 $\mathrm{nm}$ ) that was used to determine the optical LOD of the system. 



Figure 6. (a) Absorption spectrum of the green algae CC125 and the blue OLED emission spectrum; (b) Fluorescence emission spectrum of the green algae CC125 and the EQE of the PTB3/PC61BM OPD at $0 \mathrm{~V}$; (c) Algal fluorescence signal detected with the OPD for different concentrations of the herbicide Diuron; (d) Variation of the inhibition factor of algal fluorescence (calculated) as function of Diuron concentration. Reproduced from reference [78] with permission of The Royal Society of Chemistry.

The comparison of the detection by the inorganic and organic PD is shown in Figure $5 \mathrm{c}$. The LOD was $5.6 \times 10^{4}$ beads $\mu \mathrm{L}^{-1}$ (comparable to $\sim 3 \mathrm{nM}$ fluorescein) for microbeads and $1.5 \mathrm{ng} \cdot \mathrm{mL}^{-1}$ for both myoglobin and CK-MB for the human plasma immunoassays.

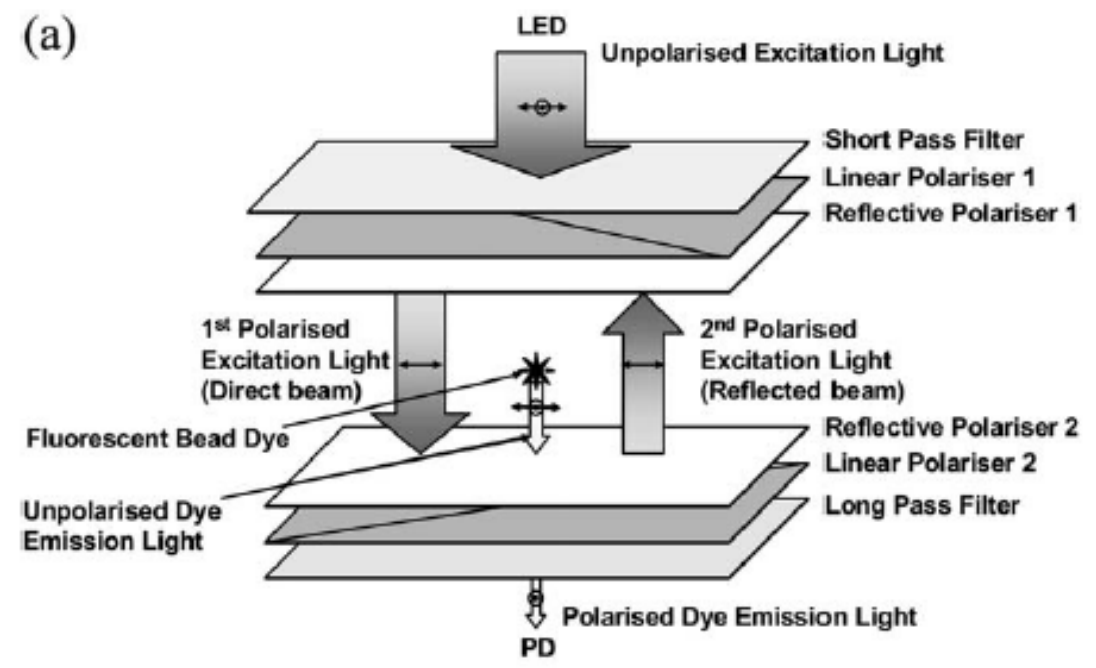

Figure 7. Cont. 

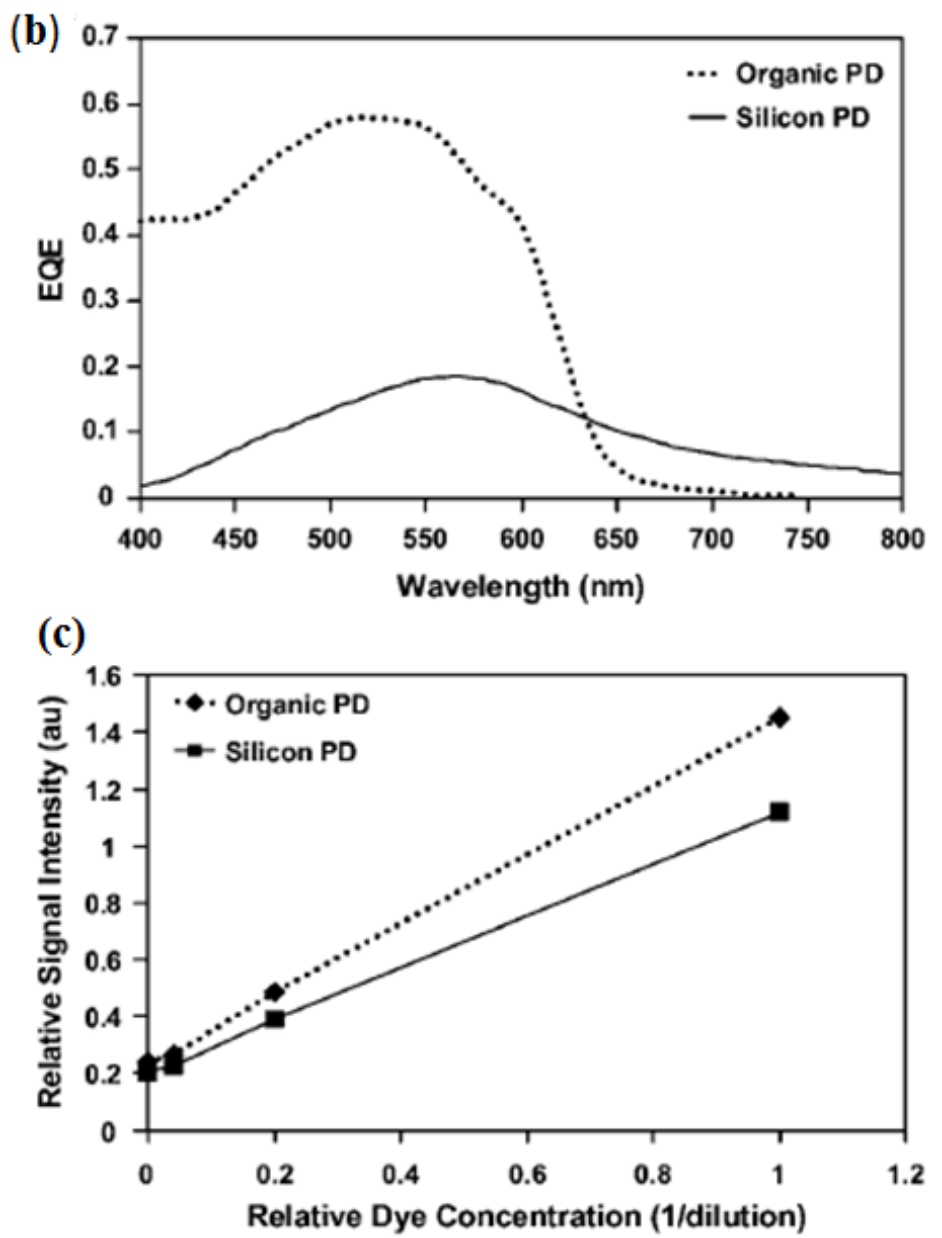

Figure 7. (a) Schematic of the sensing setup; (b) Comparison of EQE spectra of organic and Silicon PD (c) measured signal intensity as a function of TransfluoSphere bead suspension concentration using OPD and silicon PD (with IR blocking filter) Reproduced from reference [79] with permission of The Royal Society of Chemistry.

Imato and co-workers [80-83] utilized various OPDs toward an integrated optical detection system on a microchip for fluorometric immunoassays and other photometric studies. Two types of immunoassays, sandwich and competitive enzyme-linked immunosorbent assay (ELISA), for various analytes, were studied using an immobilized primary antibody (specific to the analyte) and HRP labeled secondary antibody. Amplex Red, which produces fluorescent resorufin by an enzymatic reaction with $\mathrm{HRP}$ in the presence of $\mathrm{H}_{2} \mathrm{O}_{2}$ was employed as a substrate in the assay. A LED or OLED was used to excite resorufin, the product of the immunoassay, while OPDs were used to detect the fluorescence from it. First, a heterojunction $\mathrm{CuPc} / \mathrm{C}_{60}$-based OPD with $\sim 20 \%$ IPCE was successfully employed in a flow-immunoassay for the human stress marker immunoglobulin A (IgA) with a LOD of $16 \mathrm{ng} / \mathrm{mL}$; the LOD for resorufin was $5 \mu \mathrm{M}$.

Recently, a similar OPD was used for the determination of phosphate utilizing the ion-association reaction between Malachite green (MG) and molybdenum phosphate complex [83]. The efficiency of the detection system was improved via the use of an europium (diben-zoylmethanato)3.(bathophenanthroline)-based OLED with a narrow band (FWHM $\sim 8 \mathrm{~nm}$ ) emission peaking at $612 \mathrm{~nm}$ instead of a LED, achieving a linear detection in the concentration range 
of 0-0.2 ppm with a LOD of $0.02 \mathrm{ppm}$. Later, the layered heterojunction $\mathrm{CuPc} / \mathrm{C}_{60}$ OPD was replaced with a BHJ CuPc:C60-based OPD exhibiting an improved LOD (see below) in a competitive ELISA for an environmental pollutant, alkylphenol polyethoxylates (APnEOs) [81]. The enzymatic reaction time was shortened with anti-APnEOs antibody immobilized on magnetic microbeads instead of on the microchip. The OPD was suitable for detecting the fluorescence of resorufin, attaining LODs of 2 or $4 \mathrm{ppb}$ for antibodies immobilized on the PDMS microchip or on microbeads, respectively. To enhance the efficiency further, Imato and co-workers fabricated a BHJ tris[4-(5-phenylthiopen-2-yl)phenyl]amine (10\%)(TPTPA):fullerene (C70)-based OPD. Utilizing the higher absorptivity of these materials and higher IPCE $(\sim 44 \%)$ due to the larger interface area in the BHJ structure, the OPD exhibited a linear resorufin detection range of $0-18 \mu \mathrm{M}$ with a LOD of $0.6 \mu \mathrm{M}$, whereas the LOD achieved for APnEOs was $\sim 1-2 \mathrm{ppb}$. Interestingly, although the IPCE of the TPTPA:C70-based OPD was much higher than the $\mathrm{C}_{60}$ :CuPC-based OPD, the SNR $(\sim 3)$ was very similar in all cases.

With a similar approach, Köstler and co-workers [84] demonstrated a PL-based capillary oxygen sensor. The sensing layer, comprised of a fluorescent dye embedded in a polymeric matrix, was homogeneously coated on the inner wall of a capillary tube exposed to a flowing analyte. The sensing film was optically excited by a LED through a small aperture and the sensing signal travelled through the capillary tube to the OPD formed on the external side of the capillary tube. This structure, formed on the capillary tube, was possible since the organic materials can be easily deposited on non-planar substrates. The results for oxygen sensing in the intensity mode were consistent with the expected behavior, though background light reduced the sensor's efficiency.

\subsection{Light Scattering and Absorption}

Charwat et al. [85] showed that a simple light scattering method can be very convenient for monitoring an adherent cell population using an OPD. They utilized a PDMS microfluidic biochip (Figure 7) sandwiched between two glass slides, one contained an appropriate notch filter, while the other connected the microchannels to external fluidic reservoirs. The OPD was underneath the microfluidic chip. The microfluidic channel was illuminated by a $488 \mathrm{~nm}$ collimated laser beam and the scattered light from HeLa cells was monitored by measuring the OPD's photocurrent. The latter increased with increasing cell numbers as shown in Figure 8.

Later the same group developed a miniaturized cell analysis platform by combining the OPD light scattering measurement approach with impedance spectroscopy, which enabled studying cell adhesion and cell-cell interactions in addition to monitoring the cells growth [86]. Regioregular P3HT: PC ${ }_{61} \mathrm{BM}$ BHJ OPD arrays were fabricated by spray coating on ITO-coated glass containing embedded interdigitated electrode structures (IDES) for impedance spectroscopy. Figure 9 shows the impedance spectroscopy and light scattering results of a brain metastasis prostate carcinoma cell line (DU-145) when treated with cycloheximide (CHX), which is an inhibitor of protein biosynthesis. While the change in impedance of the CHX-treated cells was insignificant compared to a control experiment, the increased light scattering by the treated DU-145 cells measured by the OPD arrays showed the rising of intracellular granularity, which is an early sign of apoptosis. Thus, the platform geometry, which provides freedom regarding sensor geometry, area, and height due to its simple spray coating fabrication, can be a useful tool for monitoring cell growth and interactions under different conditions. 


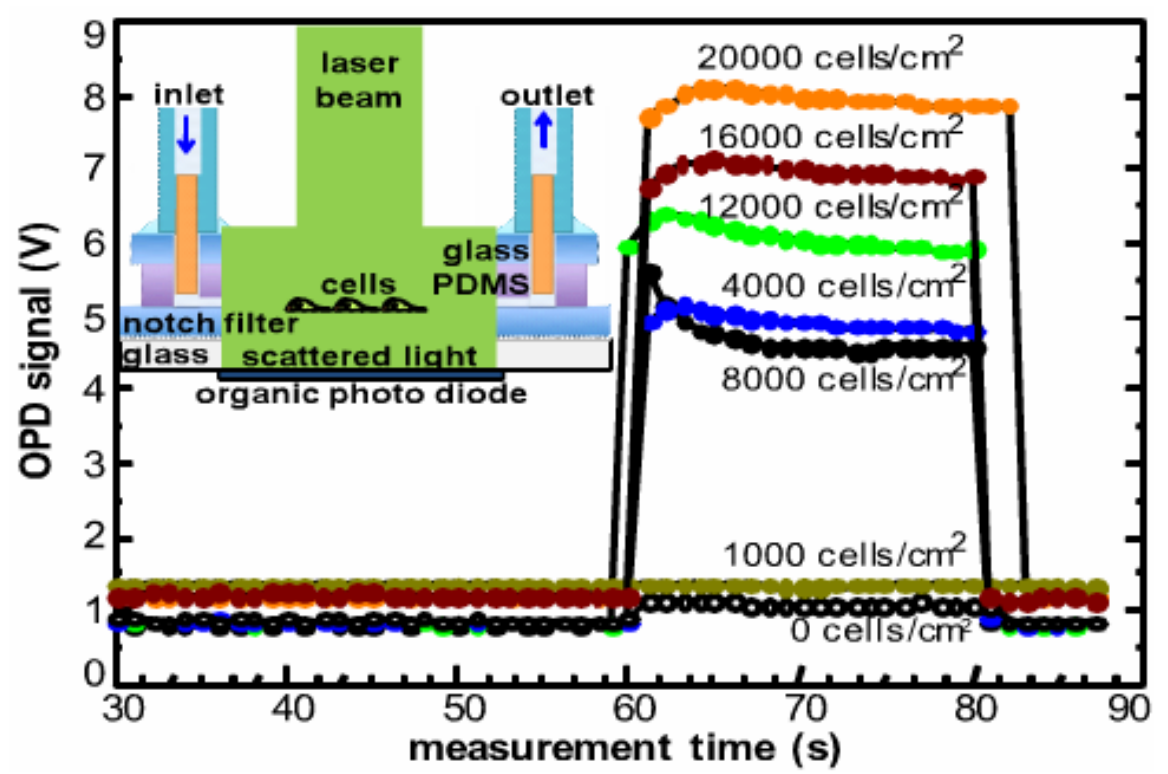

Figure 8. Light scattering raw data of increasing concentration of living HeLa cells cultivated on chip surfaces. C) 2011 IEEE; reprinted with permission, from reference [85].
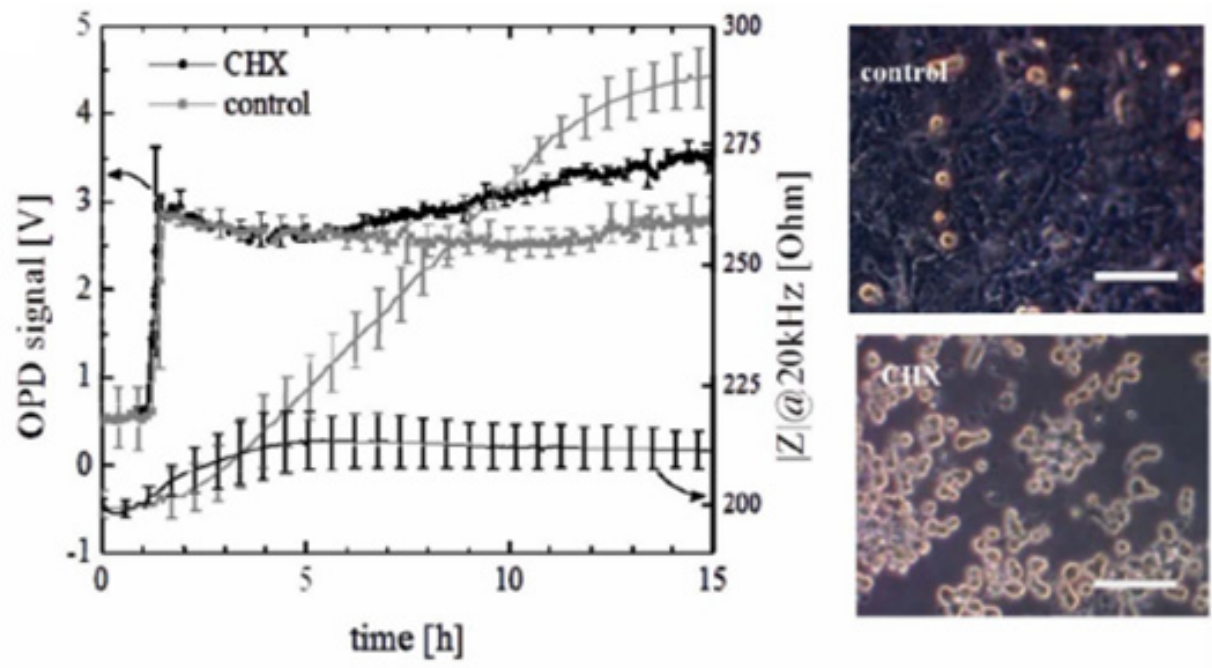

Figure 9. Averaged $(n=3)$ light scattering-time and impedance-time traces obtained for DU-145 cells (density $\sim 0.9 \times 10^{5}$ cells $/ \mathrm{cm}^{2}$ ) seeded in the absence (gray) and presence (black) of $2 \mu \mathrm{g} \cdot \mathrm{mL}^{-1}$ cycloheximide (CHX). The images show phase contrast of DU-145 carcinoma cells in the absence (control) and presence of CHX. Reproduced from reference [86] with permission of The Royal Society of Chemistry.

The integration of OPDs and OLEDs with a pulse oximetry detection system demonstrated by Lochner and coworkers shows enormous potential of such integrated systems in the medical device field [87]. As shown in Figure 10, spin-coated green (poly(9,9-dioctylfluorene-co- $N$ (4-butylphenyl)-diphenylamine)(TFB):poly((9,9-dioctylfuorene-2,7-diyl)-alt-(2,1,3-benzothiadiazole4,8-diyl)) (F8BT)-based and red (TFB:F8BT:poly((9,9-dioctylfluorene-2,7-diyl)-alt-(4,7-bis (3-hexylthiophene-5-yl)-2,1,3-benzothiadiazole)-20,20-diyl) (TBT)-based) OLEDs were fabricated on patterned ITO substrates whereas PTB7:PC $71 \mathrm{BM}$-based OPDs were printed on a polyethylene naphthalate (PEN) by the blade coating technique. The OPD exhibited high EQE at the peak emission 
wavelengths of the OLEDs (38\% and $47 \%$ for green and red OLEDs, respectively) with a low dark current of $1 \mathrm{nA} / \mathrm{cm}^{2}$ (at $-2 \mathrm{~V}$ ) and excellent stability. The OLEDs' EL was absorbed by pulsating arterial blood, non-pulsating arterial blood, venous blood and other tissues as shown in Figure 10b and the change in transmitted signal was measured by the OPD at zero bias to keep the dark current as low as possible. Light absorption in the finger is maximal during the systole phase, due to the large amount of fresh arterial blood, and minimal during the diastole,

a

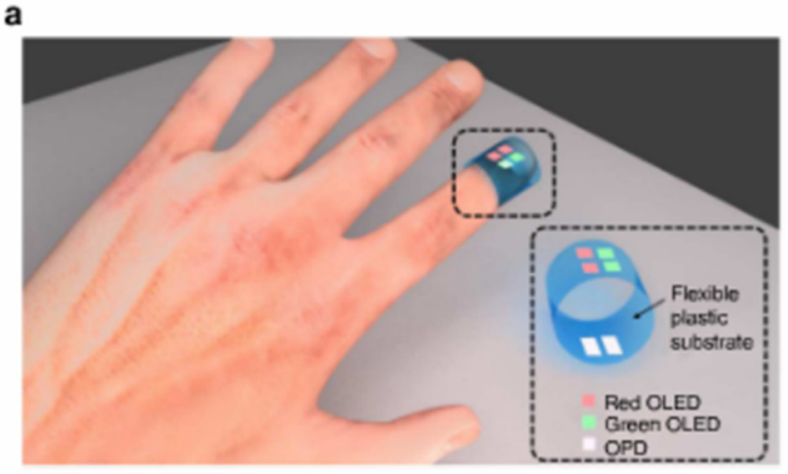

b



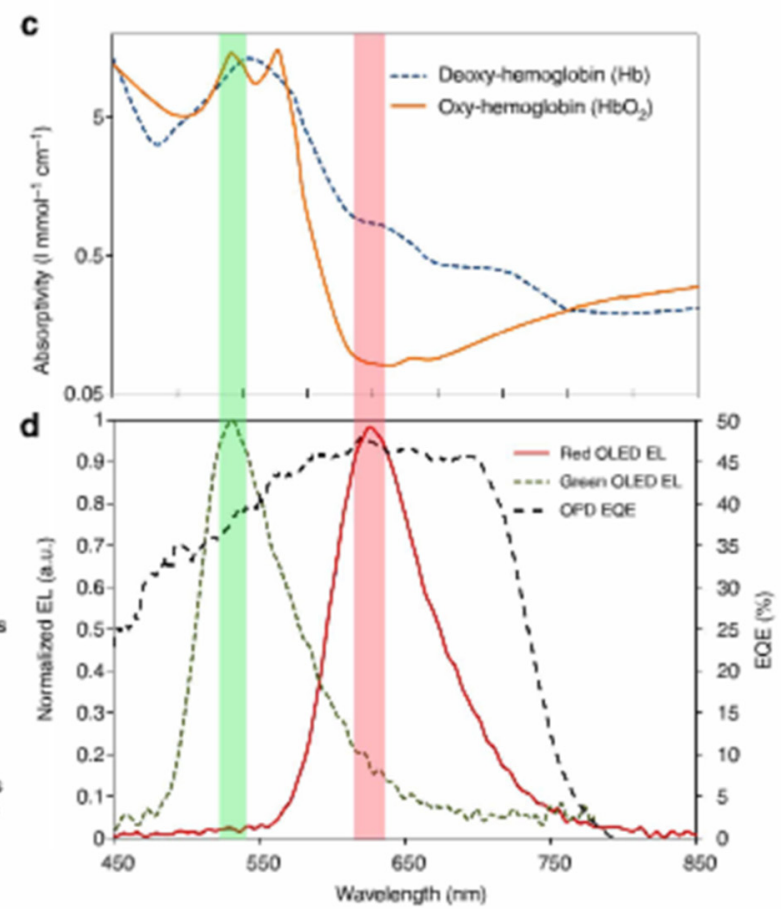

Figure 10. (a) Pulse oximetry sensor composed of two OLED arrays and two OPDs; (b) A schematic illustration of a model for the pulse oximeter's light transmission path through pulsating arterial blood, non-pulsating arterial blood, venous blood and other tissues over several cardiac cycles; (c) Absorptivity of oxygenated (orange solid line) and deoxygenated (blue dashed line) hemoglobin in arterial blood as a function of wavelength. The wavelengths corresponding to the peak OLED electroluminescence (EL) spectra are highlighted to show that there is a difference in deoxy- and oxy-hemoglobin absorptivity at the wavelengths of interest; (d) OPD EQE (black dashed line) at short circuit, and EL spectra of red (red solid line) and green (green dashed line) OLEDs. Reprinted with permission from Macmillan Publishers Ltd.: Nature communications, from reference [87] copyright (2014).

Whereas the absorption due to other parameters is unchanged. The continuous change in the OLEDs' EL transmitted through the finger when measured by the OPD gives a perfect measure of the pulse rate with only $1 \%$ error. Utilizing the difference in absorptivities of oxy- and deoxy-haemoglobin (Figure 9c), the integrated system was also successfully employed to measure arterial oxygen saturation with only $2 \%$ error. It was also shown that the background current of the OPD, under ambient light conditions, can be significantly reduced by flexing the OPD around the finger instead of keeping it flat during the measurement, thus improving the detector efficiency and accuracy. 


\subsection{On-Chip Spectrometer}

Ramuz et al. demonstrated an integrated sensing platform that involved a three stage detection scheme built on a $\mathrm{Ta}_{2} \mathrm{O}_{5}$ planar waveguide [88]. At the first stage, a photoluminescent layer of poly [2-methoxy-5-(2'-ethyl-hexyloxy)-1,4-phenylene vinylene] (MEH-PPV) located directly on top of a waveguide was excited by an iridium (III) tris(2-(4-totyl)pyridinato-N,C2) (Ir(mppy)3)-based OLED. The PL from the MEH-PPV layer was coupled into the single-mode waveguide via evanescent coupling and the guided light interacted with an analyte on its way to the detector. The interaction stage consisted of a microfluidic system, for bringing the analyte to the detection zone, and a $\mathrm{SiO}_{2} / \mathrm{TiO}_{2} / \mathrm{Cr} / \mathrm{Au} / \mathrm{TiO}_{2}$ surface plasmon resonance (SPR) stack. The interaction of the guided light occurred either via direct absorption by the labeled analyte, or via exciting a SPR mode, depending on the surface condition (change in refractive index) of the SPR stack in the presence of the analyte. In either case there is a significant absorption or a peak shift in the guided light as it reaches the outcoupling grating stage at the PD array. The rectangular gratings, machined directly in the waveguide with a period of $312 \mathrm{~nm}$ and height of $12 \mathrm{~nm}$, diffract the guided light into wavelength-specific solid angles and the light is then collected by a 40 pixels of a P3HT:PCBM-based OPD array with 70\% EQE and a lifetime of $3000 \mathrm{~h}$. Finally, this fully organic mini-spectrometer, with overall spectral resolution of $5 \mathrm{~nm}$, was employed to demonstrate an absorption-based bio-test with mouse immunoglobulin $\mathrm{G}$ (mIgG) and its antibody labeled with Cy5 marker, and for label-free detection via the SPR scheme by changing the surface refractive index of the SPR stack.

With a similar motivation to build an on-chip all organic spectrometer, Liu et al. [89] fabricated a multicolored $\mu$ COLED array, emitting in the range of 490 to $660 \mathrm{~nm}$, on a single substrate, by tuning the thickness of the optical cavity. A 2-D combinatorial array of $\mu$ COLED pixels was employed to build this compact, integrated spectrometer. To demonstrate the potential of these tunable $\mu \mathrm{cOLED}$ arrays for on-chip applications, 12 different colored pixels on a $2^{\prime \prime} \times 2$ " glass were used as the light source and the absorption of a spin-coated P3HT film on glass was measured initially using a PMT PD. In a subsequent extension of this work, a near UV 4,4'-bis(9-carbazolyl)-1,1'-biphenyl (CBP)-based combinatorial array of $\mu$ COLED pixels was fabricated by varying the thickness of the organic layers to obtain nine sharp, discrete emission peaks from 370 to $430 \mathrm{~nm}$ [77]. This array was employed in an all-organic on-chip spectrometer [77]. Figure 11a shows the schematics of the spectrometer and Figure $11 \mathrm{~b}$ shows the absorption spectrum of an Alexa fluor 405 film, a dye extensively used in biological fluorescence imaging, obtained with the spectrometer. As seen, the measured absorption is in good agreement with that of a reference measurement using an Ocean Optics spectrometer. Recapping, the current near UV array expands the range of the on-chip spectrophotometer described by Liu et al. from the visible to shorter wavelengths. 

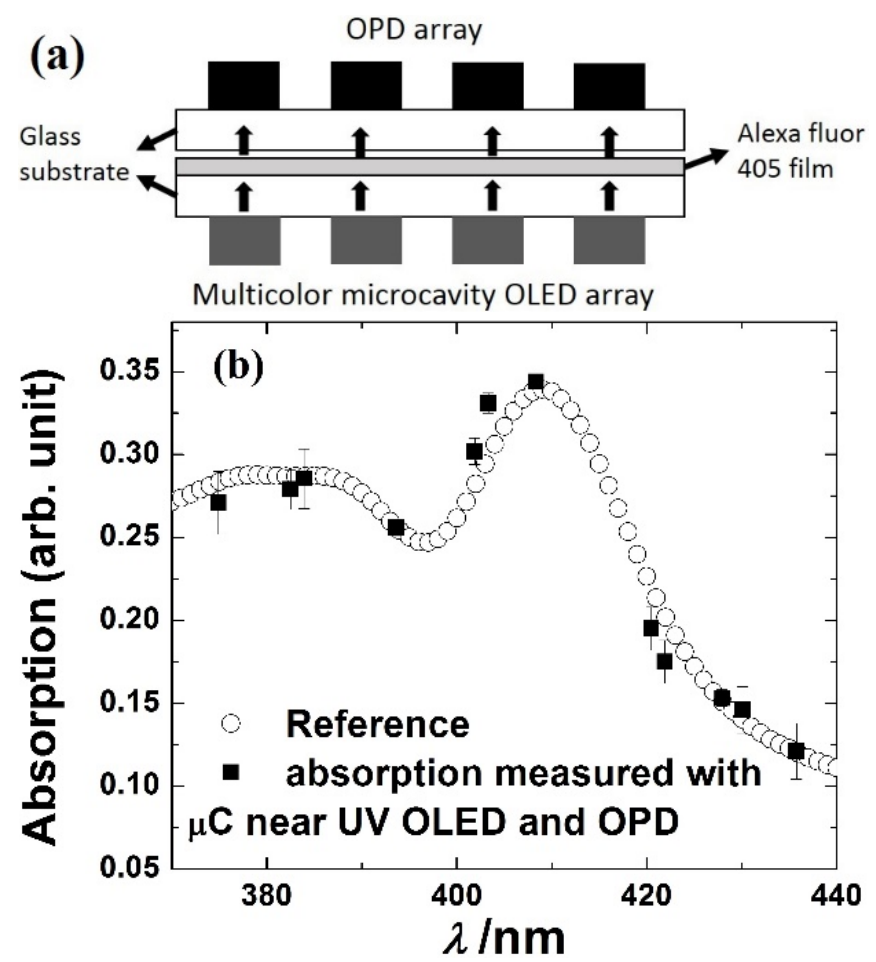

Figure 11. (a) Schematics of the all-organic on-chip spectrometer (not to scale); (b) Absorption of an Alexa fluor 405 film on glass, measured with the near UV microcavity OLED array and the ITO/PEDOT:PSS/P3HT:PCBM/Ca/Al photodetector (squares) and with an ocean optics system (circles). Figure reused from reference [77] Copyright 2015 John Wiley and Sons.

\section{Examples of Potential Challenges in Sensing with OPDs}

\subsection{Signal to Noise Ratio}

As mentioned, several promising approaches to increase the SNR of PL-based sensors were reported, however, there is still a significant barrier to achieve a low LOD. Banerjee and coworkers analyzed some of the parameters that affect the LOD [90] with the same setup they used previously [64] but with an Alq3-based green OLED, rather than a collimated metal halide lamp, as the excitation source. They repeated the detection of rhodamine $6 \mathrm{G}$ and demonstrated the effect of the depth of the microfluidic channel, the responsivity of the OPD, and the pump light power on the LOD. The SNR was theoretically shown to be maximized by suppressing the OPD's dark current that originates from the leakage EL of the excitation source and the autofluorescence from the microfluidic channel material, by using monolithic integration of the detection system for better fluorescence collection efficiency by the OPD and less leakage through the substrate. The experimental results show excellent agreement with a proposed theoretical model in terms of these three parameters. Analysis of the model shows ways to improve the SNR, thereby lowering the LOD. They report $1 \mathrm{nM}$ limit of detection of rhodamine $6 \mathrm{G}$ with a possibility of achieving even a $\mathrm{pM}$ detection level. Figure 12 shows the dependence of S/B (i.e., the signal minus the background normalized to the latter) on the OPD responsivity. 


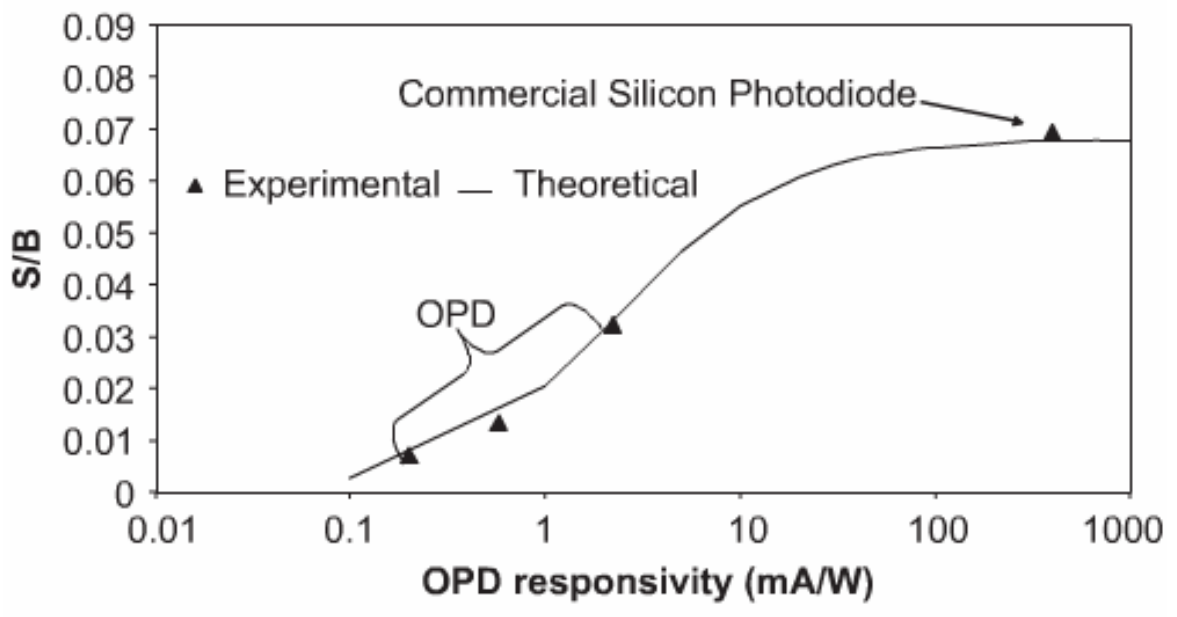

Figure 12. Variation of S/B with OPD responsivity. Measurements were conducted using $1 \mathrm{mM}$ of Rhodamine $6 \mathrm{G}$, OLED/OPD with $0.1 \mathrm{~mA} / \mathrm{W}$ responsivity and $50 \mu \mathrm{m}$ channel height with lock-in output, $5 \mathrm{~V}$ drive and $0.035 \mathrm{~mA} / \mathrm{W}$ responsivity, and lock-in-input for $50 \mu \mathrm{m}$ channel respectively. Reprinted from reference [90]; copyright 2010, with permission from Elsevier B.V.

As mentioned, another major criterion for achieving low LOD is to have very low dark current under reverse bias. Typically, low dark current densities are attained by either using a thicker active layer [20] or by using additional electron or hole blocking layers between the active layers and the electrodes $[91,92]$. The tuning of the electrode work function, by introducing a thin layer of a dielectric polymer, can also be employed to reduce the dark current via suppressing undesired carrier injection from the electrode to the active layer [93]. As an example, although a small negative bias on the OPD often improves its performance, we observed [74] that the dark current was the lowest at a level of $1 \mathrm{nA} / \mathrm{cm}^{2}$ at 0 bias, and, indeed, a bias of $-0.5 \mathrm{~V}$ deteriorated the LOD.

\subsection{Stability}

As discussed via examples throughout the text, stability of OPDs, including hybrid PDs, remains an issue. Stability of OPDs, however, is not as crucial as stability of organic solar cells, as the demand for disposable sensors is growing and sensor probes are also often disposable. Additionally, disposability of OPDs and hybrid PDs is not expected to be a major problem due to potential future low cost of such devices. Moreover, encapsulation approaches to minimize adverse effects of moisture and $\mathrm{O}_{2}$ are available as was developed for OLEDs [94-96], which will extend the operational lifetime of the OPDs. Short wavelength irradiation is known to adversely affect solar cells [97], though this is less of an issue for OPDs that are typically exposed to lower intensity longer wavelengths.

\subsection{Time Resolved Sensing with OPDs}

For time resolved sensing, short rise and fall times of the detector's response are crucial. The decay time of phosphorescent indicators is typically in the $\mu$ s range; the response time of the OPD should therefore be shorter than $1 \mu \mathrm{s}$. The response time strongly depends on material and geometric 
parameters. It was shown that it can be lowered by multilayer architectures and/or by reverse (negative) DC biasing of the OPDs [98].

It is interesting to note that an OLED-based $\mathrm{O}_{2}$ sensor with a thin film amorphous or nanocrystalline Si-based PD did not enable monitoring $\mathrm{O}_{2}$ in the time domain likely due to the presence of deep traps in the bulk of the material or at grain boundaries [99]. OPDs, in contrast, allowed such measurements $[74,75]$.

Peumans et al. [98] showed that the response time of an OPD can be shorter than 1 ns using ultrathin $(\sim 5 \AA)$ multilayer architectures with alternating D/A layers. The photogenerated excitons can then effectively diffuse to the closely spaced D/A interfaces between the CuPc and PTCBI layers, as the interfaces are within the exciton diffusion length (50 $\AA$ ). The exciton lifetime and dark current through the OPD decreased with the decreasing thickness of alternating CuPc/PTCBI layers, while the reverse bias increased the charge collection at the electrodes via field-induced exciton dissociation and carrier tunneling through the energy barriers between the layers. Interestingly, Azellino and coworkers [100] reported that the response speed of an inkjet-printed inverted P3HT:PC 61 BM OPD increases with increasing power $(\mathrm{P})$ of the incident light as at higher $\mathrm{P}$, the slow interface traps are mostly filled compared to the shallow bulk traps in the active layers, influencing exciton lifetime.

\section{Hybrid Photodetectors}

Recently organolead halide perovskite solar cells have attracted strong attention because of their high charge-carrier mobilities, strong light absorption, high quantum yield conversion, tunable spectral response, and high photoconversion efficiencies. Moreover, the performance parameters of such PDs are comparable to or better than those reported for organic and vacuum deposited inorganic PDs [101-106]. Figure 13 shows a general structure of a perovskite-based device and its energy diagram. Such devices are based on, e.g., $\mathrm{CH}_{3} \mathrm{NH}_{3} \mathrm{PbI}_{3}$ (MAI) with various choices of hole and electron transport layers, as described in the following examples.
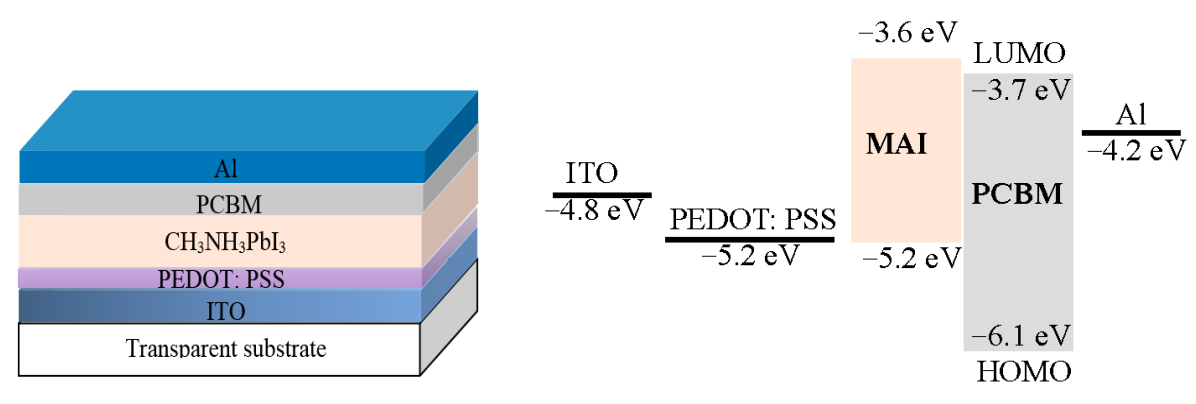

Figure 13. Schematic (not to scale) of an example of a perovskite-based device and its energy diagram.

Dou et al. [102] demonstrated a novel solution-processed organic-inorganic hybrid perovskite-based PD operating at room temperature and exhibiting a large detectivity $\left(\sim 10^{14}\right.$ Jones $)$. The structure of the PD was ITO/PEDOT:PSS/ $\mathrm{CH}_{3} \mathrm{NH}_{3} \mathrm{PbI}_{3-}{ }_{-} \mathrm{Cl}_{x} / \mathrm{PCBM} / \mathrm{PFN}$ (poly[(9,9-bis(30-(N,N-dimethylamino)propyl)2,7-fluorene)-alt-2,7-(9,9-dioctylfluorene)/Al and the reason for the high detectivity was the hole blocking layer PFN between PCBM and the Al cathode. This layer significantly reduced the dark current density to $1.5 \times 10^{-11} \mathrm{mAcm}^{-2}$, leading to a high rectification ratio $\left(\sim 10^{5}\right)$ as compared to a $\mathrm{PD}$ 
with no or other hole blocking layers. Moreover, the PD showed a linear dynamic range (LDR), over $100 \mathrm{~dB}$, and a $600 \mathrm{~ns}$ response time with a $3 \mathrm{~dB}$ bandwidth up to $3 \mathrm{MHz}$ for a $0.01 \mathrm{~cm}^{2}$ device area.

With a similar approach Fang et al. [107] fabricated a highly sensitive multilayer perovskite PD with low noise ( $16 \mathrm{fA} \mathrm{Hz}^{-1 / 2}$ at $-0.1 \mathrm{~V}$ ), close to the shot and thermal noise limits. The low noise was due mainly to trap passivation at the interfacial layer by using cross-linked OTPD ( $N 4, N 4^{\prime}$ bis(4-(6-((3-ethyloxetan-3-yl) methoxy)hexyl)phenyl)- $N 4, N 4$ '-diphenylbiphenyl-4,4'-diamine) as HTL and double fullerene layers $\left(\mathrm{PCBM} / \mathrm{C}_{60}\right)$ as ETL, which enabled the PD to resolve weak light signals of sub-picowatt $/ \mathrm{cm}^{2}$ maintaining a constant responsivity. Additionally, the PD had a high EQE ( 90\%) with a large LDR of $94 \mathrm{~dB}$ and a fast response time ( 120 ns).

The performance of perovskite PDs can also be improved by modifying the ITO/perovskite/ $\mathrm{P} 3 \mathrm{HT} / \mathrm{MoO}_{3} / \mathrm{Ag}$ OPD with a sol-gel processed $\mathrm{TiO}_{2}$ compact film as an electron extracting layer [105]. For further enhancement the $\mathrm{TiO}_{2}$ surface was reengineered with solution-processed $\mathrm{PC}_{61} \mathrm{BM}$ layer. The reduced dark current $\left(\sim 10^{-8} \mathrm{Acm}^{-2}\right)$ due to the passivation of interfacial layers resulted in a high detectivity of $4 \times 10^{12} \mathrm{~cm} \mathrm{~Hz}^{-1 / 2} \mathrm{~W}^{-1}$ over a wide wavelength range (375 to $800 \mathrm{~nm}$ ) and an EQE of $80 \%$.

The foregoing hybrid perovskite photodetectors also exhibit high photoconductive gain. Dong and coworkers showed that broadband hybrid perovskite PDs can achieve a very high gain (EQE 500\%) with a peak responsivity (i.e., the ratio of the photocurrent to incident power under $1 \mathrm{~V}$ negative bias) of $242 \mathrm{AW}^{-1}$ at $740 \mathrm{~nm}$ [108]. Xin Hu et al. demonstrated the first broadband high gain photodetector based on a $\mathrm{CH}_{3} \mathrm{NH}_{3} \mathrm{PbI}_{3}$ film deposited on a flexible ITO-coated substrate employing photoconduction under UV light [103]. The perovskite PD was found to be sensitive to a broad wavelength range from the UV to the visible, showing a photoresponsivity (defined here as the change in the photocurrent normalized to the irradiance and the device area) of $3.49 \mathrm{AW}^{-1}$ at $365 \mathrm{~nm}$ and an EQE of 5.84\% at $780 \mathrm{~nm}$ under a reverse bias of $3 \mathrm{~V}$. Additionally, the PD exhibited faster response time $(<0.1 \mu \mathrm{s})$ in comparison to other flexible PDs $[109,110]$ and an excellent electrical stability under external bending.

Despite having excellent characteristics as PDs, perovskite materials suffer from degradation in air and moisture [111,112]. Guo et al. addressed the poor performance due to the well-known instability in air and showed an effective and solution-processable passivation of the perovskite that is transparent to UV light [113]. The authors reported a $\mathrm{CH}_{3} \mathrm{NH}_{3} \mathrm{PbI}_{3-} \mathrm{Cl}_{x}$-based $\mathrm{PD}$ encapsulated by a spin-coated, water-resistant fluorous polymer (CYTOP). In addition to being highly sensitive to broadband emission, including UV, and having a sub- $\mu$ s response time, this hybrid PD maintained $75 \%$ of its initial performance after 100 days in air. The stability and durability of this device was demonstrated also by showing the insignificant change in photocurrent of the CYTOP-encapsulated perovskite PD under $8.1 \mathrm{~mW} / \mathrm{cm}^{2}$ irradiation at $50{ }^{\circ} \mathrm{C}$ (and $50 \%-60 \%$ relative humidity) for over $100 \mathrm{~h}$.

The foregoing PDs may be developed for practical applications in analytical sensing due to their broadband spectral response, high sensitivity, fast response, and low cost solution processing. We note that narrow band PDs are sometimes needed to avoid interfering excitation or other background light.

Tables 1 and 2 summarize the reported OPDs attributes and their analytical applications, respectively. Attributes of some other non-organic PDs are also provided for comparison [78,79,114-122]. Comparison to detection with a PMT [44-46] is also included in Table 2. We note that not all parameters/attributes are included in the Tables as they are not provided in the cited literature. 
Table 1. Summary of electrical and optical attributes of OPDs and some inorganic PDs.

\begin{tabular}{|c|c|c|c|c|c|c|c|c|}
\hline PD Details & $\begin{array}{c}\text { Dark Current } \\
\left(\mathbf{n A} / \mathbf{c m}^{2}\right)(\text { Bias, } V)\end{array}$ & EQE (\%) & $\begin{array}{l}\text { Responsivity } \\
\text { (A/W) }\end{array}$ & $\begin{array}{l}\text { Wavelength } \\
\text { Range (nm) }\end{array}$ & Response Time & Lifetime & Noise & References \\
\hline ITO/CuPc: $\mathrm{C}_{60} / \mathrm{BCP} / \mathrm{Al} ; \mathrm{BHJ}$ & $\sim 6.25(\sim 0)$ & 30 & & $600-700$ & & & & {$[42]$} \\
\hline $\mathrm{ITO} / \mathrm{CuPc} / \mathrm{C}_{60} / \mathrm{BCP} / \mathrm{Ag}$ & $\sim 0(+0-0.2)$ & $15-17$ & $\begin{array}{l}0.07 @ 493 \mathrm{~nm}, \\
0.11 @ 592 \mathrm{~nm}\end{array}$ & & - & - & - & {$[80]$} \\
\hline $\mathrm{ITO} / \mathrm{CuPc} / \mathrm{C}_{60} / \mathrm{BCP} / \mathrm{Ag}$ & & 23 & & $400-500$ & & & & [83] \\
\hline ITO/PEDOT:PSS/CuPc/C60/LiF/Al & $0.83(\sim 0)$ & - & $\begin{array}{c}0.008 \text { A/W@ } \\
570 \mathrm{~nm}\end{array}$ & $500-700$ & - & 2 weeks & - & {$[64,65]$} \\
\hline $\mathrm{ITO} / \mathrm{CuPc} / \mathrm{C}_{60} / \mathrm{CuPc} / \mathrm{C}_{60} / \mathrm{LiF} / \mathrm{Al}$ & - & - & $0.023 @ 560 \mathrm{~nm}$ & $500-700$ & - & - & - & {$[66]$} \\
\hline $\begin{array}{l}\text { ITO } / \mathrm{CuPc} / \mathrm{CuPc}: \mathrm{C}_{60} / \mathrm{C}_{60} / \mathrm{BCP} / \mathrm{Al} \\
\text { Mixed heterojunction }\end{array}$ & & $\begin{array}{l}\text { IPCE } 19 @ \\
585 \mathrm{~nm}\end{array}$ & & $400-750$ & & & & {$[81]$} \\
\hline $\mathrm{ITO} / \mathrm{LiF} / \mathrm{CuPc} / \mathrm{C}_{70} / \mathrm{BPhen} / \mathrm{Al}$ & - & $35 @ 640 \mathrm{~nm}$ & - & $400-700$ & - & - & - & {$[75]$} \\
\hline ITO/TPTPA:C70/BCP/Ag & & $\begin{array}{c}\text { IPCE } 44 @, \\
586 \mathrm{~nm}\end{array}$ & & $400-600$ & & & & {$[82]$} \\
\hline $\begin{array}{c}\mathrm{Au}\left(\text { or } \mathrm{Au} / \mathrm{MoO}_{3}\right) / \mathrm{CuPc} / \mathrm{PTCBI} / \mathrm{Alq}_{3} \\
(\mathrm{BPhen}) / \mathrm{Ag}\end{array}$ & $\sim 1 \mathrm{nA}$ & $10 @ 600$ nm & - & $500-700$ & $\begin{array}{c}1.3-1.6 \mu \mathrm{s} \\
\text { (with BPhen) }\end{array}$ & - & - & {$[68-73,84]$} \\
\hline $\begin{array}{l}\text { ITO/PEDOT:PSS/P3HT:PCBM/Al } \\
\text { (or } \mathrm{LiF} / \mathrm{Al}, \mathrm{Ca} / \mathrm{Al} \text { or } \mathrm{Ba} / \mathrm{Al} \text { as cathode) }\end{array}$ & $0.1-1(\sim 0-0.1)$ & $50-70$ & 0.25 & $350-600$ & $\begin{array}{c}0.51 \mu \text { s rise-time; } \\
0.66 \mu \text { s fall-time } \\
\text { (Al cathode) }\end{array}$ & $\begin{array}{l}\text { over } 3 \text { years } \\
\text { shelf life }\end{array}$ & $\begin{array}{c}\sim 1 \text { pA@1 Hz } \\
\text { band-width }\end{array}$ & {$[44-46,74,77,79,88]$} \\
\hline $\begin{array}{c}\text { ITO/PEDOT:PSS/ } \\
\text { rr-P3HT:PC } 61 \mathrm{BM} / \mathrm{Ca} / \mathrm{Ag}\end{array}$ & $\sim 65(-5)$ & $76(-5 V)$ & 0.36 & $400-650$ & - & over 1 year & $\begin{array}{c}8.2 \times 10^{-14} \\
\mathrm{~A} / \mathrm{Hz}^{1 / 2}\end{array}$ & {$[85,86]$} \\
\hline $\begin{array}{c}\text { ITO/PEDOT:PSS/PCDTBT:PC } 70 \mathrm{BM} / \\
\mathrm{LiF} / \mathrm{Al}\end{array}$ & $2.8 \times 10^{-3}(\sim 0)$ & $60-70$ & $0.22 @ 405 \mathrm{~nm}$ & $400-600$ & - & $\begin{array}{l}25 \% \text { photo-current } \\
\text { decrease in } 15 \text { days }\end{array}$ & $\begin{array}{l}\mathrm{D}^{*} \sim 9.2 \times \\
10^{11} \text { jones }\end{array}$ & {$[47,49-54]$} \\
\hline ITO/PTB3:PC $61 \mathrm{BM} / \mathrm{LiF} / \mathrm{Al}$ & $<1$ & $45 @ 685$ nm & $0.26 @ 685$ nm & $400-750$ & $1 \mu \mathrm{s}$ & - & - & {$[78]$} \\
\hline ITO/PEDOT:PSS/PTB7:PCBM/Ca/Al & $\sim 1-2(\sim 0)$ & $88 @ 640 \mathrm{~nm}$ & - & $400-700$ & - & - & - & [77] \\
\hline
\end{tabular}


Table 1. Cont.

\begin{tabular}{|c|c|c|c|c|c|c|c|c|}
\hline PD Details & $\begin{array}{c}\text { Dark Current } \\
\left(\mathbf{n A} / \mathbf{c m}^{2}\right)(\text { Bias, } \mathbf{V})\end{array}$ & EQE (\%) & $\begin{array}{c}\text { Responsivity } \\
(\mathrm{A} / \mathrm{W})\end{array}$ & $\begin{array}{l}\text { Wavelength } \\
\text { Range (nm) }\end{array}$ & Response Time & Lifetime & Noise & References \\
\hline $\begin{array}{c}\text { Conductive PEDOT:PSS/PEDOT:PSS/ } \\
\text { PTB7:PC }{ }_{71} \mathrm{BM} / \mathrm{Al}\end{array}$ & $1(-2)$ & $\begin{array}{l}38 @ 532 \mathrm{~nm} ; \\
47 @ 626 \mathrm{~nm}\end{array}$ & - & $400-750$ & & $\begin{array}{c}24 \% \text { photo-current } \\
\text { decrease over } \\
7 \text { days (OLED/OPD } \\
\text { lifetime) }\end{array}$ & & [87] \\
\hline thin film c-Si & $0.63(\sim 0)$ & - & $0.19-0.34$ & $470-600$ & - & - & - & [114] \\
\hline a-Si:H & $0.01-0.1(-3)$ & 50 & - & $500-550$ & - & - & - & {$[115,116]$} \\
\hline $\begin{array}{c}\text { (poly-Si) with interdigitated } \\
\text { p-i-n structure }\end{array}$ & $<5 \mathrm{nA}$ & 50 & 0.33 & 850 & - & - & - & {$[117]$} \\
\hline $\mathrm{PbS}$ colloidal quantum dot & 0.1 & $50 @ 550 \mathrm{~nm}$ & & $500-1400$ & $\sim 300 \mathrm{~ns}$ & $>2$ months & $\begin{array}{c}\mathrm{D}^{*} \sim 1 \times 10^{12} \\
\text { jones }\end{array}$ & {$[118]$} \\
\hline $\begin{array}{l}\text { Squaraine-based nanowire/c-Si } \\
\text { p-n heterojunction }\end{array}$ & $\sim 7 \times 10^{-3} \mathrm{nA}(-1)$ & & $1.3-9.8$ & $254-980$ & & & $\begin{array}{c}\mathrm{D}^{*} 0.06-0.45 \\
\times 10^{11} \text { jones } \\
@-3 \mathrm{~V}\end{array}$ & {$[121]$} \\
\hline
\end{tabular}


Table 2. Summary of the OPDs' analytical applications.

\begin{tabular}{|c|c|c|c|c|c|}
\hline $\begin{array}{l}\text { Detection } \\
\text { Approach }\end{array}$ & PD Type/Active Layer & Analyte & LOD & References & Comments \\
\hline \multirow{13}{*}{$\mathrm{CL}$} & $\mathrm{CuPc}: \mathrm{C}_{60} \mathrm{BHJ}$ & $\mathrm{H}_{2} \mathrm{O}_{2}$ & $1 \mathrm{mM}$ & {$[42]$} & $\begin{array}{l}\text { High LOD due to larger size of the OPD compared to } \\
\text { the detection chamber }\end{array}$ \\
\hline & \multirow{3}{*}{ P3HT:PCBM BHJ } & $\mathrm{H}_{2} \mathrm{O}_{2}$ & $10 \mu \mathrm{M}$ & {$[44]$} & \multirow{3}{*}{$\begin{array}{l}\text { Results are comparable to inorganic PD (Newport } \\
818 \text { UV Si PD) and PMT (Hamamatsu R3896 and } \\
\text { RAPTOR fiber optic biosensor) } \\
\end{array}$} \\
\hline & & Antioxidants & $1-50 \mu \mathrm{M}$ & [45] & \\
\hline & & Staphylococcal enterotoxin B & $0.5 \mathrm{ng} / \mathrm{mL}$ & [46] & \\
\hline & \multirow{7}{*}{$\begin{array}{l}\text { PCDTBT: } \mathrm{PC}_{70} \mathrm{BM} \mathrm{BHJ} \\
\text { ring shaped OPDs }\end{array}$} & rhTSH & $30-80 \mathrm{pg} / \mathrm{mL}$ & {$[47,49]$} & \multirow{7}{*}{$\begin{array}{l}\text { Higher detection sensitivity than with a P3HT based } \\
\text { PD, excellent linearity, multiplexed detection }\end{array}$} \\
\hline & & Stress hormone cortisol & $<0.28 \mathrm{nM}$ & {$[50]$} & \\
\hline & & E. coli & $5 \times 10^{5} \mathrm{cell} / \mathrm{mL}$ & \multirow{3}{*}{ [51] } & \\
\hline & & C. jejuni & $1 \times 10^{5} \mathrm{cell} / \mathrm{mL}$ & & \\
\hline & & Adenovirus & $1 \times 10^{-8} \mathrm{mg} / \mathrm{mL}$ & & \\
\hline & & $17-\beta$ estradiol & $2.5 \mathrm{pg} / \mathrm{mL}$ & {$[53]$} & \\
\hline & & Legionella pneumophila & $4 \times 10^{4} \mathrm{cell} / \mathrm{mL}$ & [54] & \\
\hline & a-Si:H & $H R P$ & $0.2 \mathrm{amol}$ & [119] & \\
\hline & $\begin{array}{l}\text { Metal semiconductor } \\
\left(\mathrm{c}-\mathrm{Si} \mathrm{n}^{+}\right) \text {metal PD }\end{array}$ & Streptavidin & $4.76 \mathrm{nM}$ & {$[120]$} & \\
\hline
\end{tabular}


Table 2. Cont.

\begin{tabular}{|c|c|c|c|c|c|}
\hline $\begin{array}{l}\text { Detection } \\
\text { Approach }\end{array}$ & $\begin{array}{l}\text { PD Type/Active } \\
\text { Layer }\end{array}$ & Analyte & LOD & References & Comments \\
\hline \multirow{17}{*}{ PL } & \multirow{5}{*}{$\mathrm{CuPc}-\mathrm{C}_{60}$} & Rhodamine $6 \mathrm{G}$ & $\begin{array}{l}10 \mathrm{nM} \text { (halide excitation), } \\
100 \mathrm{nM} \text { (OLED excitation) }\end{array}$ & \multirow[t]{2}{*}[64,65]{} & \\
\hline & & Fluorescein & $10 \mathrm{nM}$ (halide), $10 \mu \mathrm{M}$ (OLED) & & \\
\hline & & Resorufin & $5.0 \mu \mathrm{M}$ & \multirow{2}{*}[80]{} & \\
\hline & & $\operatorname{Ig} \mathrm{A}$ & $16 \mathrm{ng} / \mathrm{mL}$ & & \\
\hline & & malachite green, phosphate & $0.02 \mathrm{ppm}$ & [83] & \\
\hline & Bilayer CuPc/C60 & Rhodamine $6 \mathrm{G}$ & $10 \mathrm{nM}$ & [66] & \\
\hline & $\mathrm{CuPc} / \mathrm{C}_{70}$ & $\mathrm{O}_{2}, \mathrm{pH}$ & - & {$[75]$} & Time-resolved sensing \\
\hline & $\begin{array}{l}\mathrm{CuPc} / \mathrm{CuPc}: \mathrm{C}_{60} / \mathrm{C}_{60} \\
\text { mixed heterojunction }\end{array}$ & APnEOs & $2-4 \mathrm{ppb}$ & {$[81]$} & \\
\hline & $\mathrm{CuPc} / \mathrm{PTCBI}$ & Various indicators for $\mathrm{O}_{2}, \mathrm{CO}_{2}, \mathrm{pH}$ & - & {$[68-73,84]$} & ring shaped OPD \\
\hline & \multirow{2}{*}{ TPTPA: $\mathrm{C}_{70}$} & resorufin & $0.6 \mu \mathrm{M}$ & \multirow{2}{*}[82]{} & \multirow{2}{*}{-} \\
\hline & & APnEOs & $1-2 \mathrm{ppb}$ & & \\
\hline & \multirow{3}{*}{ P3HT:PCBM BHJ } & $\mathrm{O}_{2}, \beta$-D-glucose & - & {$[74]$} & Time resolved sensing \\
\hline & & Diuron & $11 \mathrm{nM}$ & {$[78]$} & $\begin{array}{l}\text { higher sensitivity than commercial biosensors } \\
\text { (Handy-PEA fluorometer) }\end{array}$ \\
\hline & & myoglobin, CK-MB & $1.5 \mathrm{ng} / \mathrm{mL}$ & {$[79]$} & $\begin{array}{l}\text { Higher photoresponse than Si (Osram Opto } \\
\text { Semiconductors, SFH2430) }\end{array}$ \\
\hline & PTB7:PC ${ }_{61} \mathrm{BM} \mathrm{BHJ}$ & $\mathrm{O}_{2}$ & - & {$[77]$} & - \\
\hline & \multirow[t]{2}{*}{$\mathrm{a}-\mathrm{Si}: \mathrm{H}$} & Fluorescein & $\begin{array}{c}680 \mathrm{pM} ; 17 \mathrm{nM} \text { (with integrated } \\
\text { PD on microchip) }\end{array}$ & [115] & \multirow[t]{2}{*}{ - } \\
\hline & & Green fluorescent protein & $18.5 \mathrm{nM}$ & [116] & \\
\hline \multirow{3}{*}{$\begin{array}{c}\text { Light } \\
\text { scattering }\end{array}$} & Regioregular & Living HELA cells & $<1000$ cells $/ \mathrm{cm}^{2}$ & \multirow{2}{*}[85,86]{} & \multirow{2}{*}{ Label free monitoring } \\
\hline & P3HT:PC ${ }_{61} \mathrm{BM} \mathrm{BHJ}$ & calcein-AM & - & & \\
\hline & PTB3:PC ${ }_{61}$ BM BHJ & Mouse immuno-globulin G & $5 \mathrm{~nm}$ spectral resolution & {$[88]$} & Grating-based spectrometer \\
\hline \multirow{2}{*}{ Absorption } & P3HT:PC ${ }_{61} \mathrm{BM} \mathrm{BHJ}$ & Alexa Fluor 405 & $5-10 \mathrm{~nm}$ spectral resolution & {$[77]$} & Absorption based spectrometer \\
\hline & PTB7:PC 71 BM BHJ & Oxy hemoglobin & - & [87] & Flexible integrated sensor, pulsed oximetry \\
\hline
\end{tabular}


- We note that the dark current at nominally $0 \mathrm{~V}$ bias may be due to an actual small voltage and some remnant light.

- The structure of the OPDs is planar heterojunction, unless specified otherwise.

Generally, OPDs are often comparable to their inorganic counterparts in terms of dark current and responsivity, though their response time is typically longer. Optimization of OPDs, including approaches for to increase their operational lifetime, is an ongoing field of research. Moreover, they will potentially be of low cost.

\section{Concluding Remarks and Outlook}

Compact optical bio/chem sensors have a potential to be used widely for point-of-care analyses, environmental monitoring, food safety, clinical and biological assays, and security. This review highlights some examples of successful use of organic thin film PDs as well as challenges faced in all-organic analytical devices, such as sensors and on-chip spectrometers. OPDs show good detection sensitivities and fast responses, and together with their potential low cost, flexibility of size and design, and possibility of fabrication on flexible as well as wearable substrates, they are promising as field deployable, disposable analytical tools.

There are ongoing challenges in developing all organic optical devices for analytical applications. The LOD should be improved and in some cases OPDs with specific, narrow band response (to eliminate background light), rather than broadband response, are needed. Stability is an ongoing issue, though it is not as important as in solar cells, as a demand for disposable sensors is growing. Due to the potential large selection of organic and organic-inorganic hybrid semiconductors, PDs with specific spectral response will likely be developed and the ability to fabricate micron-size devices and dense arrays will enhance their use in bioelectronics R\&D in general.

\section{Acknowledgments}

Ames Laboratory is operated by Iowa State University for the US Department of Energy (USDOE) under Contract No. DE-AC 02-07CH11358. The research was partially supported by Basic Energy Sciences, Division of Materials Science and Engineering, USDOE.

\section{Author Contributions}

The project was directed by R.S. All authors contributed to the writing, led by E.M. and R.S.

\section{Conflicts of Interest}

The authors declare no conflict of interest.

\section{References}

1. Sensors Trends 2014; Großer, V.; Heydenbluth, D.; Moos, R.; Rein, D.; Sauerer, J.; Simmons, C.T.; Sinn, W.; Werthschützky, R.; Wilde, J.; Eds.; AMA Association for Sensor Technology: Berlin, Germany, 2010. 
2. Shinar, J.; Shinar, R. Organic light-emitting devices (OLEDs) and OLED-based chemical and biological sensors: An overview. J. Phys. D Appl. Phys. 2008, doi:10.1088/0022-3727/41/ $13 / 133001$.

3. Wang, X.D.; Wolfbeis, O.S. Optical methods for sensing and imaging oxygen: Materials, spectroscopies and applications. Chem. Soc. Rev. 2014, 43, 3666-3761.

4. Williams, G.; Backhouse, C.; Aziz, H. Integration of Organic Light Emitting Diodes and Organic Photodetectors for Lab-on-a-Chip Bio-Detection Systems. Electronics 2014, 3, 43-75.

5. Ren, K.N.; Liang, Q.L.; Yao, B.; Luo, G.O.; Wang, L.D.; Gao, Y.; Wang, Y.M.; Qiu, Y. Whole column fluorescence imaging on a microchip by using a programmed organic light emitting diode array as a spatial-scanning light source and a single photomultiplier tube as detector. Lab Chip 2007, 7, 1574-1580.

6. Yao, B.; Yang, H.; Liang, Q.; Luo, G.; Wang, L.; Ren, K.; Gao, Y.; Wang, Y.; Qiu, Y. High-speed, whole-column fluorescence imaging detection for isoelectric focusing on a microchip using an organic light emitting diode as light source. Anal. Chem. 2006, 78, 5845-5850.

7. Choudhury, B.; Shinar, R.; Shinar, J. Glucose biosensors based on organic light-emitting devices structurally integrated with a luminescent sensing element. J. Appl. Phys. 2004, 96, 2949-2954.

8. Liu, R.; Cai, Y.; Park, J.-M.; Ho, K.-M.; Shinar, J.; Shinar, R. Organic Light-Emitting Diode Sensing Platform: Challenges and Solutions. Adv. Funct. Mater. 2011, 21, 4744-4753

9. Wolfbeis, O.S.; Offenbacher, H.; Kroneis, H.; Marsoner, H. A fast responding fluorescence sensor for oxygen. Microchim. Acta 1984, 82, 153-158.

10. You, Y.; Park, S.Y. A Phosphorescent Ir (III) Complex for Selective Fluoride Ion Sensing with a High Signal-to-Noise Ratio. Adv. Mater. 2008, 20, 3820-3826.

11. McDonagh, C.; MacCraith, B.D.; McEvoy, A.K. Tailoring of sol-gel films for optical sensing of oxygen in gas and aqueous phase. Anal. Chem. 1998, 70, 45-50.

12. Cai, Y.; Shinar, R.; Zhou, Z.; Shinar, J. Multianalyte sensor array based on an organic light emitting diode platform. Sens. Actuator B 2008, 134, 727-735.

13. Yu, G.; Pakbaz, K.; Heeger, A.J. Semiconducting polymer diodes: Large size, low cost photodetectors with excellent visible-ultraviolet sensitivity. Appl. Phys. Lett. 1994, 64, 3422-3424.

14. Forrest, S. The path to ubiquitous and low-cost organic electronic appliances on plastic. Nature 2004, 428, 911-918.

15. Krebs, F.C. Fabrication and processing of polymer solar cells: A review of printing and coating techniques. Sol. Energy Mater. Sol. Cells 2009, 93, 394-412.

16. Peumans, P.; Uchida, S.; Forrest, S.R. Efficient bulk heterojunction photovoltaic cells using small-molecular-weight organic thin films. Nature 2003, 425, 158-162.

17. Baierl, D.; Fabel, B.; Lugli, P.; Scarpa, G. Efficient indium-tin-oxide (ITO) free top-absorbing organic photodetector with highly transparent polymer top electrode. Org. Electron. 2011, 12, 1669-1673.

18. Abdellah, A.; Fabel, B.; Lugli, P.; Scarpa, G. Spray deposition of organic semiconducting thin-films: Towards the fabrication of arbitrary shaped organic electronic devices. Org. Electron. 2010, 11, 1031-1038.

19. Aernouts, T.; Aleksandrov, T.; Girotto, C.; Genoe, J.; Poortmans, J. Polymer based organic solar cells using ink-jet printed active layers. Appl. Phys. Lett. 2008, doi: 10.1063/1.2833185. 
20. Ng, T.N.; Wong, W.S.; Chabinyc, M.L.; Sambandan, S.; Street, R.A. Flexible image sensor array with bulk heterojunction organic photodiode. Appl. Phys. Lett. 2008, doi: 10.1063/1.2937018.

21. An, K.H.; O’Connor, B.; Pipe, K.; Shtein, M. Organic photodetector with spectral response tunable across the visible spectrum by means of internal optical microcavity. Org. Electron. 2009, 10, 1152-1157.

22. Tvingstedt, K.; Zilio, D.S.; Inganäs, O.; Tormen, M. Trapping light with micro lenses in thin film organic photovoltaic cells. Opt. Express 2008, 16, 21609-21615.

23. Zhu, K.; Neale, N.R.; Miedaner, A.; Frank, A.J. Enhanced charge-collection efficiencies and light scattering in dye-sensitized solar cells using oriented $\mathrm{TiO}_{2}$ nanotubes arrays. Nano Lett. 2007, 7, 69-74.

24. Peumans, P.; Bulović, V.; Forrest, S.R. Efficient photon harvesting at high optical intensities in ultrathin organic double-heterostructure photovoltaic diodes. Appl. Phys. Lett. 2000, 76, 2650-2652.

25. Duche, D.; Torchio, P.; Escoubas, L.; Monestier, F.; Simon, J.-J.; Flory, F.; Mathian, G. Improving light absorption in organic solar cells by plasmonic contribution. Sol. Energy Mater. Sol. Cells 2009, 93, 1377-1382.

26. Park, S.H.; Roy, A.; Beaupré, S.; Cho, S.; Coates, N.; Moon, J.S.; Moses, D.; Leclerc, M.; Lee, K.; Heeger, A.J. Bulk heterojunction solar cells with internal quantum efficiency approaching 100\%. Nat. Photonics 2009, 3, 297-303.

27. Günes, S.; Neugebauer, H.; Sariciftci, N.S. Conjugated Polymer-Based Organic Solar Cells. Chem. Rev. 2007, 107, 1324-1338.

28. Guo, F.; Xiao, Z.; Huang, J. Fullerene Photodetectors with a Linear Dynamic Range of $90 \mathrm{~dB}$ Enabled by a Cross-Linkable Buffer Layer. Adv. Opt. Mater. 2013, 1, 289-294.

29. Blum, L.J.; Marquette, C.A. Chemiluminescence-based sensors. In Optical Chemical Sensors; Baldini, F., Chester, A.N., Homola, J., Martellucci, S., Eds.; Springer Science \& Business Media: Dordrecht, The Netherlands, 2006; pp. 157-178.

30. Juris, A.; Balzani, V.; Barigelletti, F.; Campagna, S. Ru (II) polypyridine complexes: Photophysics, photochemistry, eletrochemistry, and chemiluminescence. Coord. Chem. Rev. 1988, 84, 85-277.

31. Flecha, B.G.; Llesuy, S.; Boveris, A. Hydroperoxide-initiated chemiluminescence: An assay for oxidative stress in biopsies of heart, liver, and muscle. Free Radic. Biol. Med. 1991, 10, 93-100.

32. Sigvardson, K.W.; Kennish, J.M.; Birks, J.W. Peroxyoxalate chemiluminescence detection of polycyclic aromatic amines in liquid chromatography. Anal. Chem. 1984, 56, 1096-1102.

33. Allen, R.C.; Loose, L.D. Phagocytic activation of a luminol-dependent chemiluminescence in rabbit alveolar and peritoneal macrophages. Biochem. Biophys. Res. Commun. 1976, 69, 245-252.

34. Boveris, A.; Cadenas, E.; Chance, B. Ultraweak chemiluminescence: A sensitive assay for oxidative radical reactions. Fed. Proc. 1981, 40, 195-198.

35. Braman, R.S.; Hendrix, S.A. Nanogram nitrite and nitrate determination in environmental and biological materials by vanadium (III) reduction with chemiluminescence detection. Anal. Chem. 1989, 61, 2715-2718.

36. Hanaoka, N.; Tanaka, H.; Nakamoto, A.; Takada, M. Kinetic study of background emission from peroxyoxalate chemiluminescence reaction and application to the improvement of detection limits in liquid chromatography. Anal. Chem. 1991, 63, 2680-2685. 
37. Andrew, K.N.; Sanders, M.G.; Forbes, S.; Worsfold, P.J. Flow methods for the determination of polycyclic aromatic hydrocarbons using low power photomultiplier tube and charge coupled device chemiluminescence detection. Anal. Chim. Acta 1997, 346, 113-120.

38. Amatatongchai, M.; Hofmann, O.; Nacapricha, D.; Chailapakul, O.; de Mello, A.J. A microfluidic system for evaluation of antioxidant capacity based on a peroxyoxalate chemiluminescence assay. Anal. Bioanal. Chem. 2007, 387, 277-285.

39. Gachanja, A.; Worsfold, P. Determination of aliphatic carboxylic acids in non-aqueous matrices by liquid chromatography with peroxyoxalate chemiluminescence detection. Anal. Chim. Acta 1994, 290, 226-232.

40. Knight, A.W.; Greenway, G.M.; Chesmore, E.D. Development of a silicon photodiode, electrogenerated chemiluminescence, flow-through detector. Anal. Proc. 1995, 32, 125-127.

41. Pereira, A.T.; Novo, P.; Prazeres, D.; Chu, V.; Conde, J.P. Heterogeneous immunoassays in microfluidic format using fluorescence detection with integrated amorphous silicon photodiodes. Biomicrofluidics 2011, doi: 10.1063/1.3553014.

42. Hofmann, O.; Miller, P.; Sullivan, P.; Jones, T.S.; de Mello, J.C.; Bradley, D.D.C.; de Mello, A.J. Thin-film organic photodiodes as integrated detectors for microscale chemiluminescence assays. Sens. Actuators B 2005, 106, 878-884.

43. Jorgensen, A.M.; Mogensen, K.B.; Kutter, J.P.; Geschke, O. A biochemical microdevice with an integrated chemiluminescence detector. Sens. Actuators B 2003, 90, 15-21.

44. Wang, X.; Hofmann, O.; Das, R.; Barrett, E.; de Mello, A.J.; de Mello, J.C.; Bradley, D. Integrated thin-film polymer/fullerene photodetectors for on-chip microfluidic chemiluminescence detection. Lab Chip 2007, 7, 58-63.

45. Wang, X.; Amatatongchai, M.; Nacapricha, D.; Hofmann, O.; de Mello, J.C.; Bradley, D.D.C.; de Mello, A.J. Thin-film organic photodiodes for integrated on-chip chemiluminescence detection-application to antioxidant capacity screening. Sens. Actuators B 2009, 140, 643-648.

46. Wojciechowski, J.; Shriver-Lake, L.; Yamaguchi, M.; Füreder, E.; Pieler, R.; Schamesberger, M.; Winder, C.; Prall, H.; Sonnleitner, M.; Ligler, F. Organic Photodiodes for Biosensor Miniaturization. Anal. Chem. 2009, 81, 3455-3461.

47. Pires, N.; Dong, T. Polycarbazole-based organic photodiodes for highly sensitive chemiluminescent immunoassays. In Proceedings of the Annual International Conference of the IEEE Engineering in Medicine and Biology Society, Osaka, Japan, 3-7 July 2013; pp. 1700-1703.

48. Lim, K.-G.; Choi, M.-R.; Kim, H.-B.; Park, J.H.; Lee, T.-W. High-efficiency polymer photovoltaic cells using a solution-processable insulating interfacial nanolayer: The role of the insulating nanolayer. J. Mater. Chem. 2012, 22, 25148-25153.

49. Pires, N.; Dong, T.; Hanke, U.; Hoivik, N. Integrated optical microfluidic biosensor using a polycarbazole photodetector for point-of-care detection of hormonal compounds. J. Biomed. Opt. 2013, doi:10.1117/1.JBO.18.9.097001.

50. Pires, N.M.; Dong, T. Detection of stress hormones by a microfluidic-integrated polycarbazole/fullerene photodetector. In Proceedings of the 2013 35th Annual International Conference of the IEEE Engineering in Medicine and Biology Society (EMBC), Osaka, Japan, 3-7 July 2013; pp. 4470-4473. 
51. Pires, N.M.M.; Dong, T. Microfluidic Biosensor Array with Integrated Poly (2,7-Carbazole)/ Fullerene-Based Photodiodes for Rapid Multiplexed Detection of Pathogens. Sensors 2013, 13, 15898-15911.

52. Honrado, C.; Dong, T. Development and optimization of an integrated capillary-based opto-microfluidic device for chemiluminescence quantitative detection. J. Micromech. Microeng. 2014, doi:10.1088/0960-1317/24/12/125023.

53. Pires, N.; Dong, T. Ultrasensitive opto-microfluidic immunosensor integrating gold nanoparticle enhanced chemiluminescence and highly stable organic photodetector. J. Biomed. Opt. 2014, doi:10.1117/1.JBO.19.3.030504.

54. Pires, N.; Dong, T. An integrated passive-flow microfluidic biosensor with organic photodiodes for ultra-sensitive pathogen detection in water. In Proceedings of the 36th Annual International Conference of the IEEE Engineering in Medicine and Biology Society (EMBC), Chicago, IL, 26-30 August 2014; pp. 4411-4414.

55. Hartmann, P.; Leiner, M.J.; Lippitsch, M.E. Luminescence quenching behavior of an oxygen sensor based on a Ru (II) complex dissolved in polystyrene. Anal. Chem. 1995, 67, 88-93.

56. Wolfbeis, O.S.; Klimant, I.; Werner, T.; Huber, C.; Kosch, U.; Krause, C.; Neurauter, G.; Dürkop, A. Set of luminescence decay time based chemical sensors for clinical applications. Sens. Actuators B 1998, 51, 17-24.

57. O’Riordan, T.C.; Buckley, D.; Ogurtsov, V.; O’Connor, R.; Papkovsky, D.B. A cell viability assay based on monitoring respiration by optical oxygen sensing. Anal. Biochem. 2000, 278, 221-227.

58. Sailor, M.J.; Wu, E.C. Photoluminescence-Based Sensing with Porous Silicon Films, Microparticles, and Nanoparticles. Adv. Funct. Mater. 2009, 19, 3195-3208.

59. Shinar, R.; Ghosh, D.; Choudhury, B.; Noack, M.; Dalal, V.L.; Shinar, J. Luminescence-based oxygen sensor structurally integrated with an organic light-emitting device excitation source and an amorphous Si-based photodetector. J. Non-Cryst. Solids 2006, 352, 1995-1998.

60. Berezin, M.Y.; Achilefu, S. Fluorescence Lifetime Measurements and Biological Imaging. Chem. Rev. 2010, 110, 2641-2684.

61. Kautsky, H. Quenching of luminescence by oxygen. Trans. Faraday Soc. 1939, 35, 216-219.

62. Choudhury, B.; Shinar, R.; Shinar, J. Luminescent chemical and biological sensors based on the structural integration of an OLED excitation source with a sensing component. Proc. SPIE 2004, 5214, 64-71.

63. Shinar, R.; Choudhury, B.; Zhou, Z.; Wu, H.-S.; Tabatabai, L.B.; Shinar, J. Structurally integrated organic light-emitting device-based sensors for oxygen, glucose, hydrazine, and anthrax. Proc. SPIE 2004, 5588, 59-69.

64. Banerjee, A.; Pais, A.; Papautsky, I.; Klotzkin, D. A Polarization Isolation Method for High-Sensitivity, Low-Cost on-Chip Fluorescence Detection for Microfluidic Lab-on-a-Chip. IEEE Sens. J. 2008, 8, 621-627.

65. Pais, A.; Banerjee, A.; Klotzkin, D.; Papautsky, I. High-sensitivity, disposable lab-on-a-chip with thin-film organic electronics for fluorescence detection. Lab Chip 2008, 8, 794-800. 
66. Shuai, Y.; Banerjee, A.; Klotzkin, D.; Papautsky, I. On-chip fluorescence detection with organic thin film devices for disposable lab-on-a-chip sensors. In Proceedings of the 2008 IEEE Sensors, Lecce, Italy, 26-29 October 2008.

67. Banerjee, A.; Shuai, Y.; Klotzkin, D.; Papautsky, I. High-Sensitivity Mems Based On-Chip Fluorescence Detection System: Measurement and Analysis of Ultimate Sensitivity Limits. In Proceedings of the 17th Biennial University/Government/Industry Micro/Nano Symposium, Louisville, KY, USA, 13-16 July 2008; pp. 177-182.

68. Kraker, E.; Haase, A.; Lamprecht, B.; Jakopic, G.; Konrad, C.; Köstler, S. Integrated organic electronic based optochemical sensors using polarization filters. Appl. Phys. Lett. 2008, doi:10.1063/1.2837410.

69. Mayr, T.; Abel, T.; Kraker, E.; Köstler, S.; Haase, A.; Konrad, C.; Tscherner, M.; Lamprecht, B. An optical sensor array on a flexible substrate with integrated organic opto-electric devices. Procedia Eng. 2010, 5, 1005-1008.

70. Abel, T.; Sagmeister, M.; Lamprecht, B.; Kraker, E.; Köstler, S.; Ungerböck, B.; Mayr, T. Filter-free integrated sensor array based on luminescence and absorbance measurements using ring-shaped organic photodiodes. Anal. Bioanal. Chem. 2012, 404, 2841-2849.

71. Lamprecht, B.; Sagmeister, M.; Kraker, E.; Hartmann, P.; Jakopic, G.; Köstler, S.; Ditlbacher, H.; Galler, N.; Krenn, J.; Ungerböck, B.; et al. Integrated waveguide sensor platform utilizing organic photodiodes. Proc. SPIE 2012, doi:10.1117/12.908432.

72. Sagmeister, M.; Lamprecht, B.; Kraker, E.; Haase, A.; Jakopic, G.; Köstler, S.; Ditlbacher, H.; Galler, N.; Abel, T.; Mayr, T. Integrated organic optical sensor arrays based on ring-shaped organic photodiodes. Proc. SPIE 2011, doi: 10.1117/12.893497.

73. Sagmeister, M.; Tschepp, A.; Kraker, E.; Abel, T.; Lamprecht, B.; Mayr, T.; Köstler, S. Enabling luminescence decay time-based sensing using integrated organic photodiodes. Anal. Bioanal. Chem. 2013, 405, 5975-5982.

74. Nalwa, K.S.; Cai, Y.; Thoeming, A.L.; Shinar, J.; Shinar, R.; Chaudhary, S. Polythiophene-fullerene based photodetectors: Tuning of spectral response and application in photoluminescence based (bio)chemical sensors. Adv. Mater. 2010, 22, 4157-4161.

75. Liu, R.; Xiao, T.; Cui, W.; Shinar, J.; Shinar, R. Multiple approaches for enhancing all-organic electronics photoluminescent sensors: Simultaneous oxygen and $\mathrm{pH}$ monitoring. Anal. Chim. Acta 2013, 778, 70-78.

76. Liu, R.; Gan, Z.; Shinar, R.; Shinar, J. Transient Electroluminescence Spikes in Small Molecular Organic Light-Emitting Diodes. Phys. Rev. B 2011, doi: 10.1103/PhysRevB.83.245302.

77. Manna, E.; Fungura, F.; Biswas, R.; Shinar, J.; Shinar, R. Tunable Near UV Microcavity OLED Arrays: Characterization and Analytical Applications. Adv. Funct. Mater. 2015, 25, 1226-1232.

78. Lefèvre, F.; Chalifour, A.; Yu, L.; Chodavarapu, V.; Juneau, P.; Izquierdo, R. Algal fluorescence sensor integrated into a microfluidic chip for water pollutant detection. Lab Chip 2012, 12, 787-793.

79. Ryu, G.; Huang, J.; Hofmann, O.; Walshe, C.A.; Sze, J.Y.; McClean, G.D.; Mosley, A.; Rattle, S.J.; Bradley, D.D. Highly sensitive fluorescence detection system for microfluidic lab-on-a-chip. Lab Chip 2011, 11, 1664-1670. 
80. Miyake, M.; Nakajima, H.; Hemmi, A.; Yahiro, M.; Adachi, C.; Soh, N.; Ishimatsu, R.; Nakano, K.; Uchiyama, K.; Imato, T. Performance of an organic photodiode as an optical detector and its application to fluorometric flow-immunoassay for IgA. Talanta 2012, 96, 132-139.

81. Ishimatsu, R.; Naruse, A.; Liu, R.; Nakano, K.; Yahiro, M.; Adachi, C.; Imato, T. An organic thin film photodiode as a portable photodetector for the detection of alkylphenol polyethoxylates by a flow fluorescence-immunoassay on magnetic microbeads in a microchannel. Talanta 2013, 117, $139-145$.

82. Liu, R.; Ishimatsu, R.; Yahiro, M.; Adachi, C.; Nakano, K.; Imato, T. Fluorometric flow-immunoassay for alkylphenol polyethoxylates on a microchip containing a fluorescence detector comprised of an organic light emitting diode and an organic photodiode. Talanta 2015, 134, 37-47.

83. Liu, R.; Ishimatsu, R.; Yahiro, M.; Adachi, C.; Nakano, K.; Imato, T. Photometric flow injection determination of phosphate on a PDMS microchip using an optical detection system assembled with an organic light emitting diode and an organic photodiode. Talanta 2015, 132, 96-105.

84. Lamprecht, B.; Tschepp, A.; Čajlaković, M.; Sagmeister, M.; Ribitsch, V.; Köstler, S.A. luminescence lifetime-based capillary oxygen sensor utilizing monolithically integrated organic photodiodes. Analyst 2013, 138, 5875-5878.

85. Charwat, V.; Muellner, P.; Hainberger, R.; Purtscher, M.; Ertl, P.; Tedde, S.; Hayden, O. Monitoring light scattering characteristics of adherent cell cultures using a lab-on-a-chip. In Proceedings of the 2011 ICO International Conference on Information Photonics (IP), Ottawa, ON, Canada, 18-20 May 2011; pp. 1-2.

86. Charwat, V.; Purtscher, M.; Tedde, S.; Hayden, O.; Ertl, P. Standardization of microfluidic cell cultures using integrated organic photodiodes and electrode arrays. Lab Chip 2013, 13, 785-797.

87. Lochner, C.M.; Khan, Y.; Pierre, A.; Arias, A.C. All-organic optoelectronic sensor for pulse oximetry. Nat. Commun. 2014, doi:10.1038/ncomms6745.

88. Ramuz, M.; Leuenberger, D.; Bürgi, L. Optical biosensors based on integrated polymer light source and polymer photodiode. J. Polym. Sci. Part B Polym. Phys. 2011, 49. 80-87.

89. Liu, R.; Xu, C.; Biswas, R.; Shinar, J.; Shinar, R. $\mathrm{MoO}_{3}$ as combined hole injection layer and tapered spacer in combinatorial multicolor microcavity organic light emitting diodes. Appl. Phys. Lett. 2011, doi:10.1063/1.3623482.

90. Banerjee, A.; Shuai, Y.; Dixit, R.; Papautsky, I.; Klotzkin, D. Concentration dependence of fluorescence signal in a microfluidic fluorescence detector. J. Lumin. 2010, 130, 1095-1100.

91. Keivanidis, P.; Khong, S.-H.; Ho, P.; Greenham, N.; Friend, R. All-solution based device engineering of multilayer polymeric photodiodes: Minimizing dark current. Appl. Phys. Lett. 2009, doi:10.1063/1.3120547.

92. Gong, X.; Tong, M.-H.; Park, S.; Liu, M.; Jen, A.; Heeger, A. Semiconducting Polymer Photodetectors with Electron and Hole Blocking Layers: High Detectivity in the Near-Infrared. Sensors 2010, 10, 6488-6496.

93. Saracco, E.; Bouthinon, B.; Verilhac, J.-M.; Celle, C.; Chevalier, N.; Mariolle, D.; Dhez, O.; Simonato, J.-P. Work Function Tuning for High-Performance Solution-Processed Organic Photodetectors with Inverted Structure. Adv. Mater. 2013, 25, 6534-6538.

94. Ghosh, A.P.; Gerenser, L.J.; Jarman, C.M.; Fornalik, J.E. Thin-film encapsulation of organic light-emitting devices. Appl. Phys. Lett. 2005, doi:10.1063/1.1929867. 
95. Park, J.-S.; Chae, H.; Chung, H.K.; Lee, S.I. Thin film encapsulation for flexible AM-OLED: A review. Semicond. Sci. Technol. 2011, doi:10.1088/0268-1242/26/3/034001.

96. Ahmad, J.; Bazaka, K.; Anderson, L.J.; White, R.D.; Jacob, M.V. Materials and methods for encapsulation of OPV: A review. Renew. Sustain. Energy Rev. 2013, 27, 104-117.

97. Jørgensen, M.; Norrman, K.; Krebs, F.C. Stability/degradation of polymer solar cells. Sol. Energy Mater. Sol. Cells 2008, 92, 686-714.

98. Peumans, P.; Bulović, V.; Forrest, S.R. Efficient, high-bandwidth organic multilayer photodetectors. Appl. Phys. Lett. 2000, 76, 3855-3857.

99. Ghosh, D.; Shinar, R.; Dalal, V.; Zhou, Z.; Shinar, J. Amorphous and nanocrystalline p-i-n Si and $\mathrm{Si}, \mathrm{Ge}$ photodetectors for structurally integrated $\mathrm{O}_{2}$ sensors. J. Non-Cryst. Solids 2008, 354, 2606-2609.

100. Azzellino, G.; Grimoldi, A.; Binda, M.; Caironi, M.; Natali, D.; Sampietro, M. Fully Inkjet Printed Organic Photodetectors with High Quantum Yield. Adv. Mater. 2013, 25, 6829-6833.

101. Miyasaka, T. Perovskite Photovoltaics: Rare Functions of Organo Lead Halide in Solar Cells and Optoelectronic Devices. Chem. Lett. 2015, 44, 720-729.

102. Dou, L.; Yang, Y.M.; You, J.; Hong, Z.; Chang, W.H.; Li, G.; Yang, Y. Solution-processed hybrid perovskite photodetectors with high detectivity. Nat. Commun. 2014, doi:10.1038/ncomms6404.

103. Hu, X.; Zhang, X.; Liang, L.; Bao, J.; Li, S.; Yang, W.; Xie, Y. High-Performance Flexible Broadband Photodetector Based on Organolead Halide Perovskite. Adv. Funct. Mater. 2014, 24, 7373-7380.

104. Lee, Y.; Kwon, J.; Hwang, E.; Ra, C.H.; Yoo, W.J.; Ahn, J.H.; Park, J.H.; Cho, J.H.; High-Performance Perovskite-Graphene Hybrid Photodetector. Adv. Mater. 2015, 27, 41-46.

105. Liu, C.; Wang, K.; Yi, C.; Shi, X.; Du, P.; Smith, A.W.; Karim, A.; Gong, X. Ultrasensitive solution-processed perovskite hybrid photodetectors. J. Mater. Chem. C 2015, 3, 6600-6606.

106. Xiao, Z.; Yuan, Y.; Shao, Y.; Wang, Q.; Dong, Q.; Bi, C.; Sharma, P.; Gruverman, A.; Huang, J. Giant switchable photovoltaic effect in organometal trihalide perovskite devices. Nat. Mater. 2015, 14, 193-198.

107. Fang, Y.; Huang, J. Resolving Weak Light of Sub-picowatt per Square Centimeter by Hybrid Perovskite Photodetectors Enabled by Noise Reduction. Adv. Mater. 2015, 27, 2804-2810.

108. Dong, R.; Fang, Y.; Chae, J.; Dai, J.; Xiao, Z.; Dong, Q.; Yuan, Y.; Centrone, A.; Zeng, X.C.; Huang, J. High-Gain and Low-Driving-Voltage Photodetectors Based on Organolead Triiodide Perovskites. Adv. Mater. 2015, 27, 1912-1918.

109. Wang, F.X.; Lin, J.; Gu, W.B.; Liu, Y.Q.; Wu, H.D.; Pan, G.B. Aerosol-jet printing of nanowire networks of zinc octaethylporphyrin and its application in flexible photodetectors. Chem. Commun. 2013, 49, 2433-2435.

110. Chen, G.; Liu, Z.; Liang, B.; Yu, G.; Xie, Z.; Huang, H.T.; Liu, B.; Wang, X.F.; Chen, D.; Zhu, M.Q.; et al. Single-Crystalline p-Type Zn3As2 Nanowires for Field-Effect Transistors and Visible-Light Photodetectors on Rigid and Flexible Substrates. Adv. Funct. Mater. 2013, 23, 2681-2690.

111. Misra, R.K.; Aharon, S.; Li, B.; Mogilyansky, D.; Visoly-Fisher, I.; Etgar, L.; Katz, E.A. Temperature- and Component-Dependent Degradation of Perovskite Photovoltaic Materials under Concentrated Sunlight. J. Phys. Chem. Lett. 2015, 6, 326-330. 
112. Niu, G.; Li, W.; Meng, F.; Wang, L.; Dong, H.; Qiu, Y. Study on the stability of $\mathrm{CH}_{3} \mathrm{NH}_{3} \mathrm{PbI}_{3}$ films and the effect of post-modification by aluminum oxide in all-solid-state hybrid solar cells. J. Mater. Chem. A 2014, 2, 705-710.

113. Guo, Y.; Liu, C.; Tanaka, H.; Nakamura, E. Air-Stable and Solution-Processable Perovskite Photodetectors for Solar-Blind UV and Visible Light. J. Phys. Chem. Lett. 2015, 6, 535-539.

114. Dhar, S.; Miller, D.M.; Jokerst, N.M. High responsivity, low dark current, heterogeneously integrated thin film Si photodetectors on rigid and flexible substrates. Opt. Express. 2014, 22, 5052-5059.

115. Kamei, T.; Paegel, B.M.; Scherer, J.R.; Skelley, A.M.; Street, R.A.; Mathies, R.A. Integrated Hydrogenated Amorphous Si Photodiode Detector for Microfluidic Bioanalytical Devices. Anal. Chem. 2003, 75, 5300-5305.

116. Joskowiak, A.; Santos, M.S.; Prazeres, D.M.F.; Chua, V.; Condea, J.P. Integration of thin film amorphous silicon photodetector with lab-on-chip for monitoring protein fluorescence in solution and in live microbial cells. Sens. Actuators. B 2011, 156, 662-667.

117. Samusenko, A.; Hamedan, V.J.; Pucker, G.; Ghulinyan, M.; Ficorella, F.; Guider, R.; Gandolfi, D.; Pavesi, L. Integrated silicon photodetector for lab-on-chip sensor platform. Proc. SPIE 2015, doi:10.1109/AISEM.2015.7066813.

118. Clifford, J.P.; Konstantatos, G.; Johnston, K.W.; Hoogland, S.; Levina, L.; Sargen, E.H. Fast, sensitive and spectrally tuneable colloidal quantum-dot photodetectors. Nat. Nanotechnol. 2009, $4,40-44$

119. Caputo, D.; de Cesare, G.; Dolci, L.S.; Mirasoli, M.; Nascetti, A.; Roda, A.; Scipinotti, R. Microfluidic chip with integrated a-Si:H photodiodes for chemiluminescence-based bioassays. IEEE Sens. J. 2013, 13, 2595-2602.

120. Lin, C.C.; Ko, F.H.; Chen, C.C.; Yang, Y.S.; Chang, F.C.; Wu, C.S. Miniaturized metal semiconductor metal photocurrent system for biomolecular sensing via chemiluminescence. Electrophoresis 2009, 30, 3189-3197.

121. Deng, W.; Jie, J.; Shang, Q.; Wang, J.; Zhang, X.; Yao, S.; Zhang, Q.; Zhang, X. Organic Nanowire/Crystalline Silicon p-n Heterojunctions for High-Sensitivity, Broadband Photodetectors ACS Appl. Mater. Interfaces 2015, 7, 2039-2045.

122. Pires, N.N.M.; Dong, T.; Hanke, U.; Hoivik, N. Recent Developments in Optical Detection Technologies in Lab-on-a-Chip Devices for Biosensing Applications. Sensors 2014, 14, $15458-15479$.

(C) 2015 by the authors; licensee MDPI, Basel, Switzerland. This article is an open access article distributed under the terms and conditions of the Creative Commons Attribution license (http://creativecommons.org/licenses/by/4.0/). 